\title{
Profile and Management of Toxicity of Selinexor and Belantamab Mafodotin for the Treatment of Triple Class Refractory Multiple Myeloma
}

\author{
Karun Neupane (D) \\ Ahsan Wahab ${ }^{2}$ \\ Adeel Masood (iD) 3 \\ Tehniat Faraz (iD) 4 \\ Saman Bahram ${ }^{5}$ \\ Hamid Ehsan (iD ${ }^{6}$ \\ Abdul Hannan ${ }^{7}$ \\ Faiz Anwer ${ }^{8}$
}

'Department of Internal Medicine, Manipal College of Medical Sciences, Pokhara, Gandaki, Nepal; ${ }^{2}$ Department of Internal Medicine, Baptist Medical Center South/University of Alabama at

Birmingham, Montgomery, AL, USA;

${ }^{3}$ Department of Internal Medicine, Tidal Health Peninsula Regional, Salisbury, MD, USA; ${ }^{4}$ Department of Biochemistry, Dow University of Health Sciences, Karachi, Sindh, Pakistan; ${ }^{5}$ Department of Internal Medicine, Dow University of Health Sciences, Karachi, Sindh, Pakistan;

${ }^{6}$ Department of Biomedic Sciences/ Biohazardous Threat Agents \& Emerging Infectious Diseases, Georgetown University, Washington, DC, USA; ${ }^{7}$ Department of Hematology/Oncology, Simmons Cancer Institute at Southern Illinois University School of Medicine, Springfield, IL, USA; ${ }^{8}$ Department of Hematology/Oncology, Cleveland Clinic Taussig Cancer Institute, Cleveland, $\mathrm{OH}$, USA
Correspondence: Karun Neupane Department of Internal Medicine, Manipal College of Medical Sciences, Phulbari, Pokhara, Gandaki, 33700, Nepal Email krn.neupane49@gmail.com

\begin{abstract}
Treatment options are limited for multiple myeloma patients who have developed four/five drug-refractory disease. Selinexor (Sel) and belantamab mafodotin (belamaf) were recently approved by the US FDA for treatment of RRMM. The toxicity profile of these drugs is a concern since these agents are used in patients who have already undergone multiple lines of treatment. In this review, we discuss the toxicity profile and strategies for the management of toxicities of Sel and belamaf for the treatment of RRMM. We conducted a comprehensive literature search on PubMed, Embase, Cochrane, and Clinicaltrials.gov using the terms "selinexor", "belantamab", "belamaf", and "multiple myeloma" without applying any limitations based on the date of the study, language, or country of origin. The most common hematological toxicity associated with these two drugs is thrombocytopenia. Cytopenias, constitutional symptoms, gastrointestinal effects, and hyponatremia are the major toxicities of Sel. Keratopathy and anemia are the major toxicities of belamaf. Treatment modifications and dose interruption are usually needed when side effects are more than grade II. As these are newer drugs with limited data, continuous surveillance and monitoring are warranted during the treatment course with early mitigation strategies.
\end{abstract}

Keywords: hematological malignancy, treatment, safety, ocular toxicity, relapsed and refractory multiple myeloma

\section{Introduction}

Multiple myeloma (MM) is the second most prevalent hematologic cancer that led to approximately 12,830 deaths in the US during 2020. ${ }^{1}$ However, the advent of newer drugs has improved its five-year survival rate. A vast majority of MM patients require subsequent lines of therapy following relapses. ${ }^{2}$ Treatment options are limited for those who develop the triple-class refractory disease (ie, refractory to immunomodulators (IMiDs), proteasome inhibitors (PIs), and anti-CD38 monoclonal antibodies) pressing the need for the development of newer drugs that can overcome this resistance to conventional therapy. ${ }^{3}$

\section{Overview of Selinexor}

Selinexor (KPT-330) is an oral, reversible inhibitor of major nuclear exporter of tumor suppressor proteins (TSPs) known as Exportin-1 (XPO1) or chromosomal maintenance 1 (CRM1) (Figure 1). XPO1 binds to the guanosine triphosphate (GTP)-binding nuclear protein called Ran and forms the XPO1/Ran GTP 


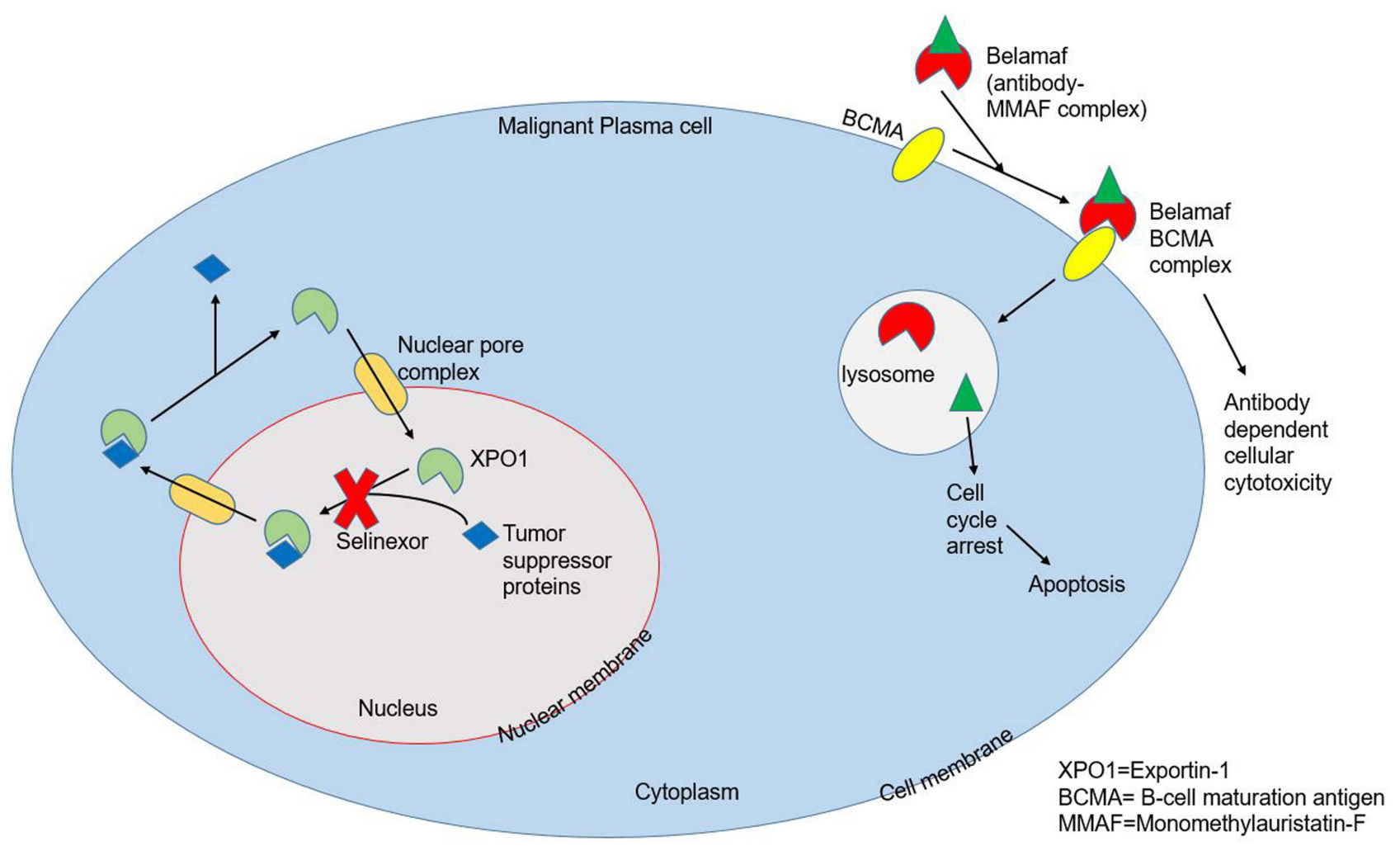

Figure I Mechanism of action of Selinexor and Belamaf.

nucleocytoplasmic transport complex which is responsible for the transport of many TSPs out of the nucleus such as p53, breast cancer gene 1/2 (BRCA1/2), forkhead box-O (FOXO) and growth regulatory factors (c-myc, cyclins, Mouse Double Minute 2 homolog (MDM2)). When overexpressed, XPO1 causes an aberrant distribution of these regulatory proteins localizing them within the cytoplasm, increasing the translation of oncoprotein mRNAs and functionally inactivating TSPs which gives the malignant cells a chance to evade apoptosis and thus proliferate. As a selective inhibitor of nuclear export (SINE), selinexor (Sel) causes forced nuclear retention of these compounds with subsequent cell cycle arrest and cancer cell death, largely sparing the normal cells. ${ }^{3-5}$

Following the encouraging results of the pivotal Phase II STORM trial, ${ }^{5,6} \mathrm{Sel}$ in combination with low-dose dexamethasone (Dexa) was approved by the Food and Drug Administration (FDA) of the United States in July $2019^{7}$ for quadrefractory (refractory to at least 2 PIs and two IMiDs) or penta-refractory MM (quadrefractory+ refractory to anti-CD38 antibodies). ${ }^{3,8}$ The adverse events (AEs) reported in the $\mathrm{STORM}^{6}{ }^{6} \mathrm{STOMP}^{3}$ and $\mathrm{BOSTON}^{9}$ trials were mostly manageable with supportive measures. Cytopenias, constitutional and gastrointestinal symptoms, and hyponatremia were the most common AEs in these trials, with grade (G)-3 or severe thrombocytopenia occurring in $54 \%$ of patients. ${ }^{5,10}$

\section{Overview of Belantamab Mafodotin}

B-cell maturation antigen (BCMA), almost exclusively expressed on plasma cells, is an attractive drug target for the treatment of drug-resistant MM. ${ }^{11,12}$ Belantamab mafodotin (belamaf), an anti-BCMA agent, received FDA approval in August 2020 for the treatment of adults with refractory MM who have previously received at least four therapies including PIs, IMiDs, and anti-CD38 monoclonal antibody. ${ }^{13}$ Belamaf is an antibody-drug conjugate (ADC) in which afucosylated humanized IgG1-antibody is conjugated to microtubule inhibitor monomethyl auristatin-F (MMAF) that kills myeloma cells through a multimodal mechanism (Figure 1). This ADC complex targets BCMA and induces immunogenic cell death through antibody-dependent cellular cytotoxicity and cellular phagocytosis. The cytotoxic component of ADC, ie, MMAF when delivered to the target B-cells inhibits tubulin polymerization causing cell cycle arrest at the G2/M checkpoint and subsequent apoptosis. ${ }^{11,14,15}$ The use of singleagent belamaf has produced encouraging results in the 
pivotal DREAMM 1 and 2 trials, with an overall response rate (ORR) of $60 \%$ in DREAMM-1, and $31 \%$ for $2.5 \mathrm{mg} /$ $\mathrm{kg}$ vs $34 \%$ for $3.4 \mathrm{mg} / \mathrm{kg}$ cohorts of DREAMM-2. ${ }^{15-17}$ The most common AE, keratopathy, occurring in $27 \%$ and $16 \%$ of patients receiving $2.5 \mathrm{mg} / \mathrm{kg}$ and $3.5 \mathrm{mg} / \mathrm{kg}$ doses of belamaf respectively, was manageable with supportive care along with dose adjustments and resolved after treatment completion. Thrombocytopenia and anemia were the next most common AEs. ${ }^{18,19}$

This review aims to discuss the toxicities associated with the use of Sel and belamaf in the treatment of heavily pretreated RRMM (relapsed/refractory MM) and to evaluate the management of these toxicities in the light of available evidence.

\section{Materials and Methods}

We conducted a comprehensive literature search on four databases including PubMed, Embase, Cochrane, and Clinicaltrials.gov. We used the search terms "selinexor", "belantamab", and "multiple myeloma". We did not apply any limitations based on the date of publication, language, or country of origin. The initial search resulted in 430 total articles. After removing duplicates and screening manually to only include articles based on human studies and those that have reported on the safety profile or management of toxicity of the two drugs belamaf and Sel, 100 articles were selected for review, including six studies on Sel and two studies on belamaf. The selection of the articles was confirmed by two authors.

\section{Results \\ Dose, Combination Regimens, and Toxicity Profile of Selinexor}

The dose of Sel ranged from $3-85 \mathrm{mg} / \mathrm{m}^{2}$ in the first-inhuman trial where Sel was used in 189 patients with advanced solid malignancies. The starting dose of $3 \mathrm{mg} /$ $\mathrm{m}^{2}$ was extrapolated from non-human studies. ${ }^{20}$ Chen et al. investigated the safety of Sel in heavily pretreated MM patients $(n=84)$. They administered $3-60 \mathrm{mg} / \mathrm{m}^{2}$ of oral Sel either in eight doses or 10 doses per 28-day cycle in the dose-escalation phase $(n=25)$. In the dose-expansion phase $(\mathrm{n}=59)$, they administered Sel 45 or $60 \mathrm{mg} / \mathrm{m}^{2}$ twice-weekly along with $20 \mathrm{mg}$ of Dexa in a 28-day cycle vs Sel alone with the same flat doses in the 21-day cycle. $^{2}$ Sel-Dexa combination vs Sel alone showed better overall response rates (ORR), ie, $22 \%$ vs $4 \%$, and lower rates of serious AEs (SAEs), ie, 39\% vs 61\%. Given the fewer dosage modifications, Sel $45 \mathrm{mg} / \mathrm{m}^{2}$ ( $\left.\sim 80 \mathrm{mg}\right)$ twice-weekly with $20 \mathrm{mg}$ Dexa emerged as an appropriate treatment regimen for future studies. ${ }^{2}$ The STORM phase II trial parts 1 and 2 used the same regimen of Sel-Dexa, ie, $80 \mathrm{mg}$ of Sel twice-weekly along with $20 \mathrm{mg}$ of Dexa in a 28-day cycle in 79 patients and 122 patients, respectively, and yielded ORR of $21 \%$ and $26 \% .^{5,6}$ The STOMP phase $\mathrm{Ib} / 2$ study evaluated Sel-Dexa combination with bortezomib (Bort) in 42 RRMM patients. Once-weekly administration of Sel $100 \mathrm{mg}$, Dexa $40 \mathrm{mg}$, and Bort 1.3 $\mathrm{mg} / \mathrm{m}^{2}$ per 35 -day cycle was the most tolerable regimen vs other tested regimens, with an ORR of $58 \%$. Those without PI refractoriness had an ORR of $84 \%$ vs $43 \%$ for PIrefractory $\mathrm{MM}^{3}$ The Phase III BOSTON trial used the same weekly regimen of Sel-Dexa-Bort/35-day cycle and compared it with the 21-day cycle of Bort $\left(1.3 \mathrm{mg} / \mathrm{m}^{2}\right)$ Dexa $(20 \mathrm{mg})$ twice-weekly for 8 weeks followed by Bort $\left(1.3 \mathrm{mg} / \mathrm{m}^{2}\right)$ once-weekly and Dexa $20 \mathrm{mg}$ twice-weekly. ${ }^{9}$ Though G-3/4 hematologic (thrombocytopenia: 39\% vs $17 \%$, anemia: $16 \%$ vs $10 \%$ ) and G-3/4 non-hematologic AEs except peripheral neuropathy (fatigue: $13 \%$ vs $1 \%$, nausea: $8 \%$ vs $0 \%$, peripheral neuropathy: $5 \%$ vs $9 \%$ ) were more common with Sel-Dexa-Bort vs Bort-Dexa, once-weekly combination of Sel-Dexa-Bort showed superior median PFS (HR: 0.7, 95\% CI: 0.53-0.93) and ORR (OR: 1.96, 95\% CI: 1.3-3.1) compared to Bort-Dexa. ${ }^{3}$ Recently, Jakubowiak et al evaluated the twice-weekly combination of Sel-Dexa with carfilzomib (Carf) in 21 patients with RRMM. This was a dose-escalation trial with the Sel dose ranging from 20-60 mg twice-weekly along with Carf and Dexa. ${ }^{21}$ The recommended twiceweekly doses in this trial were Sel $60 \mathrm{mg}$, Carf 20/27 $\mathrm{mg} / \mathrm{m} 2$ and Dexa $20 \mathrm{mg}$. Overall, G-3/4 thrombocytopenia (71\%) and infections (24\%) were the most common hematologic and non-hematologic AEs in this trial. ${ }^{21}$

The common G-3/4 hematological AEs as reported by these studies $2,3,5,9,20,21$ were thrombocytopenia (39-71\%), anemia (16-33\%), leukopenia (8-33\%) and neutropenia (9-33\%) whereas common G-3/4 non-hematological AEs were hyponatremia (5-26\%), fatigue (13-15\%), diarrhea (5-10\%), eye disorders (9-10\%), musculoskeletal disorders (4-10\%), elevated liver enzymes (10\%), peripheral neuropathy $(5 \%)$ and vomiting $(2-4 \%)$. Gastrointestinal (GI) AEs such as nausea, vomiting, diarrhea, weight loss were mainly G-1/2 and usually reversible. The toxicities reported by these studies are summarized in Table 1. SAEs (27-63\%) responsible for complications in Sel \pm Dexa trials included infections (respiratory infections $(n=16)$, 


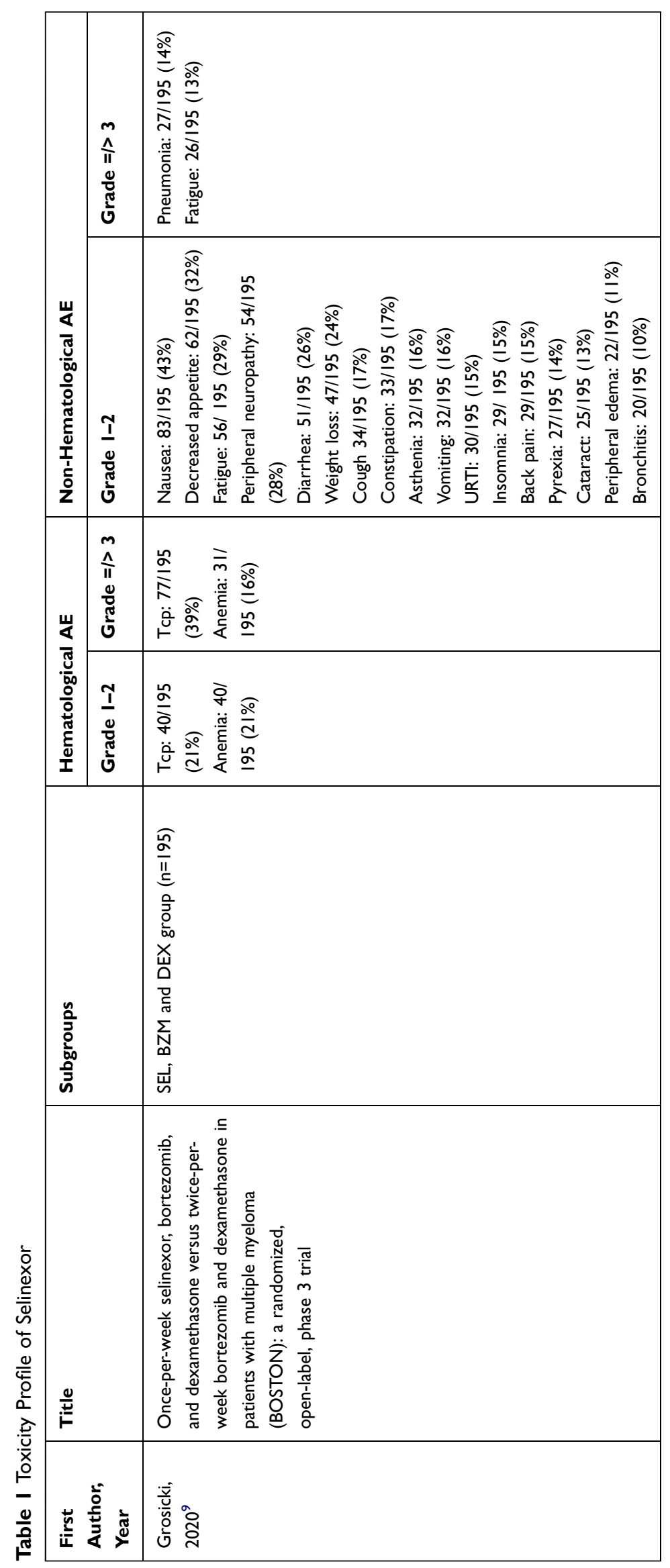




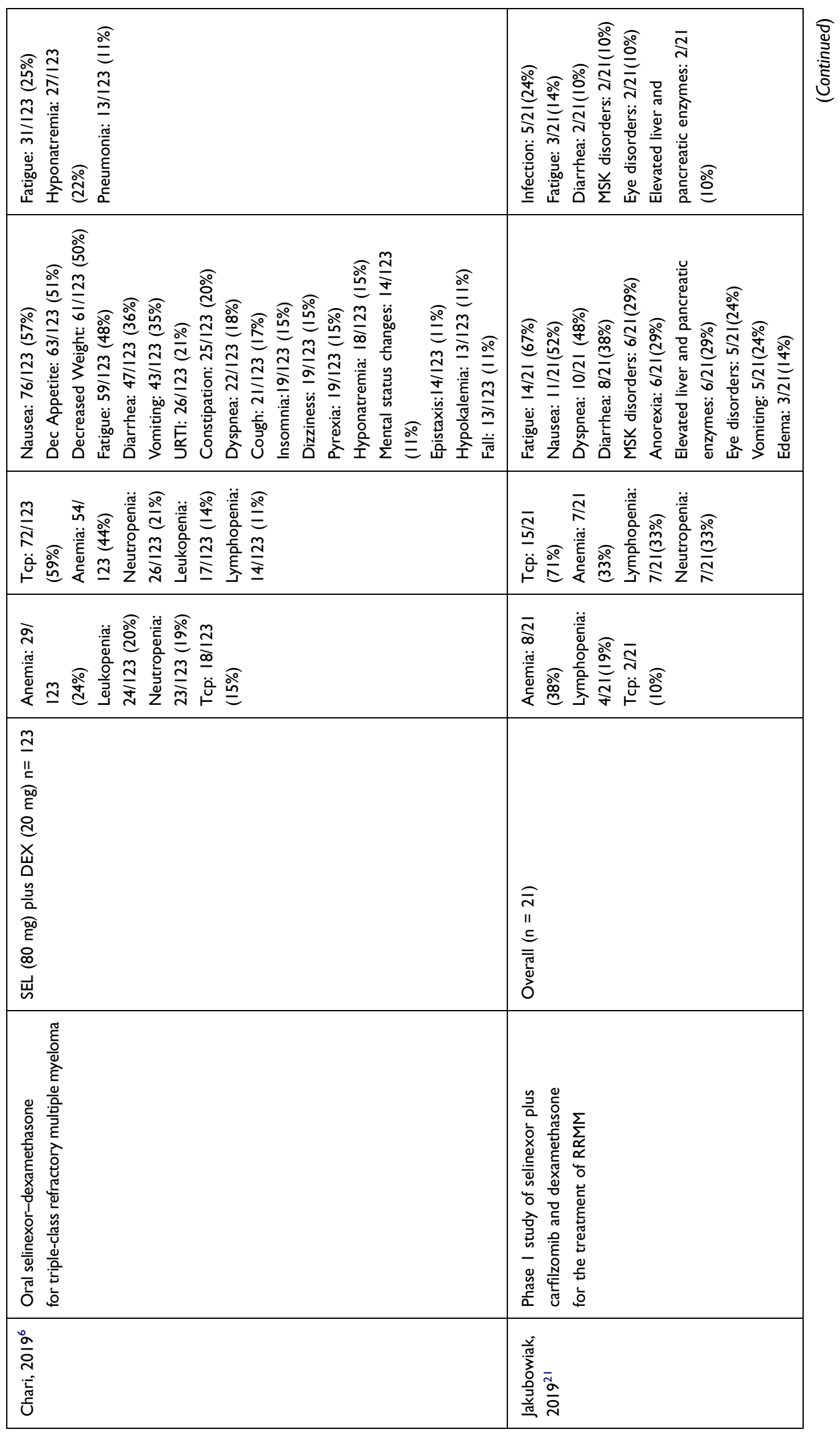




\begin{tabular}{|c|c|c|c|c|}
\hline & 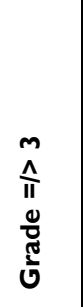 & 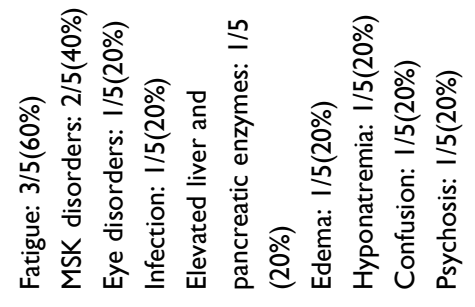 & 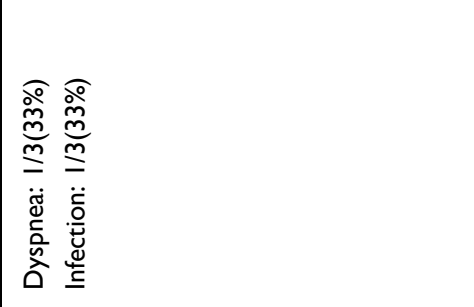 & 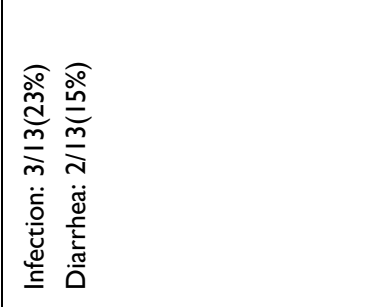 \\
\hline 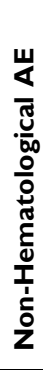 & $\frac{T}{\frac{T}{0}}$ & 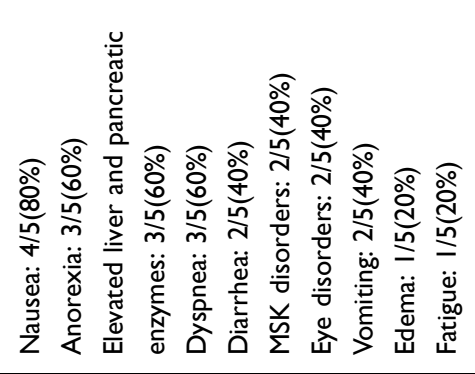 & 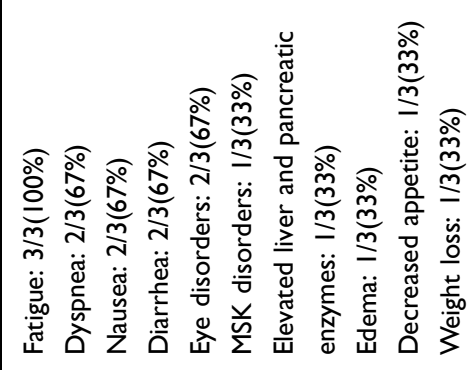 & 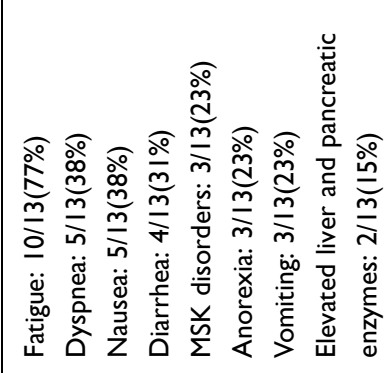 \\
\hline$\stackrel{\amalg}{\longleftarrow}$ & 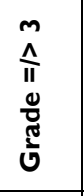 & 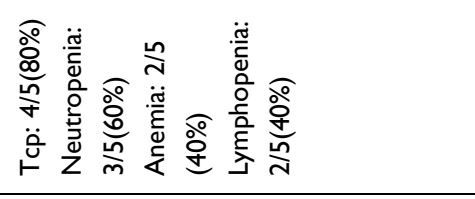 & 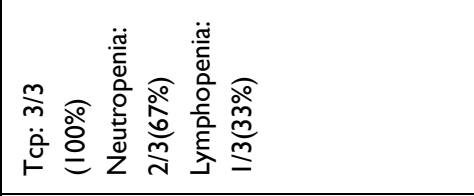 & 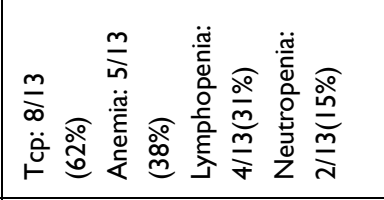 \\
\hline 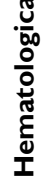 & $\begin{array}{l}\frac{1}{0} \\
\frac{\pi}{\pi} \\
0\end{array}$ & 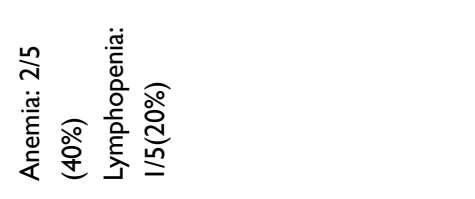 & 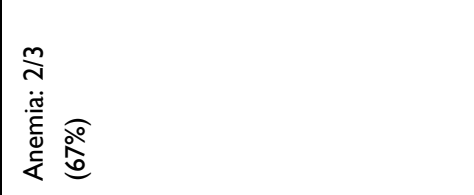 & 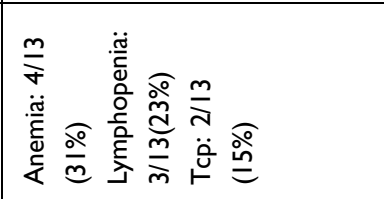 \\
\hline 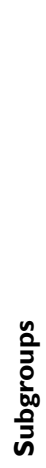 & & 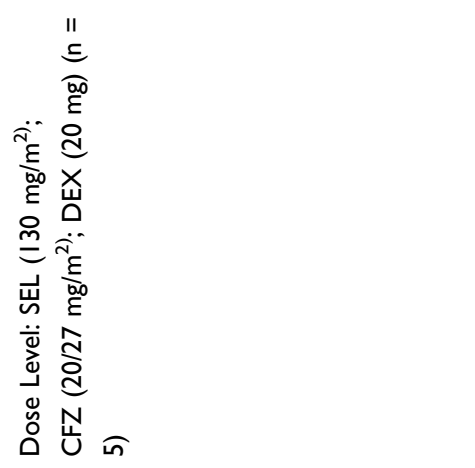 & 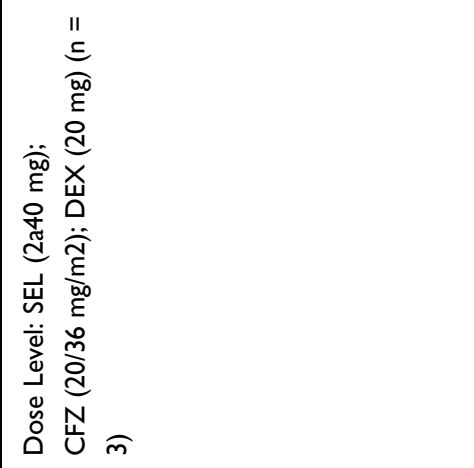 & 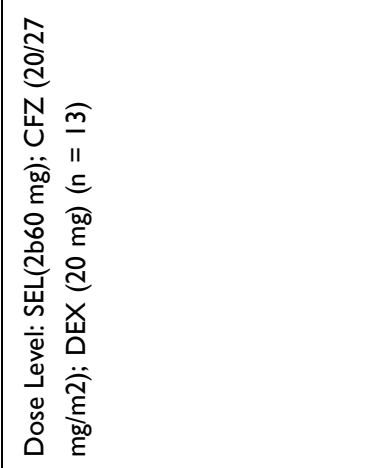 \\
\hline \multicolumn{5}{|l|}{$\cong$} \\
\hline \multicolumn{5}{|c|}{ 䓂站竞离 } \\
\hline
\end{tabular}




\begin{tabular}{|c|c|c|}
\hline 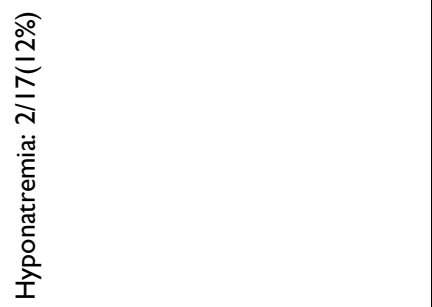 & 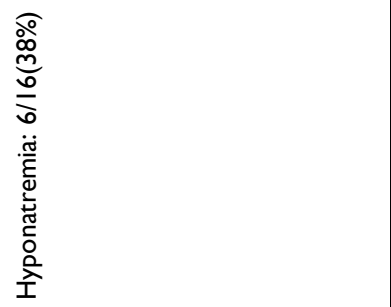 & 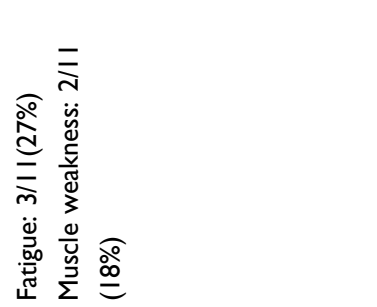 \\
\hline 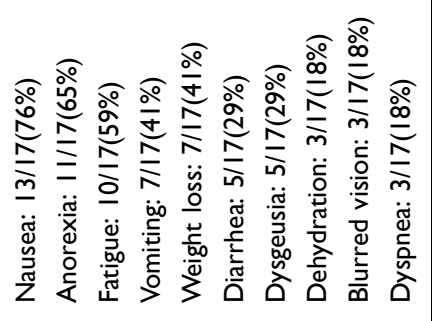 & 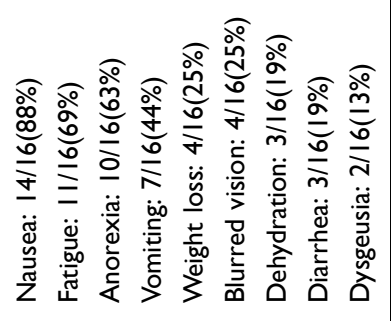 & 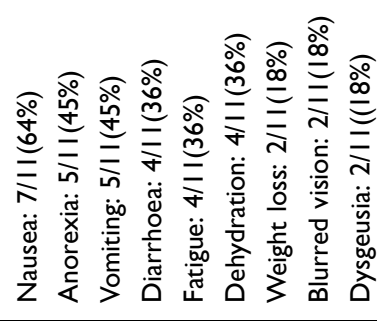 \\
\hline 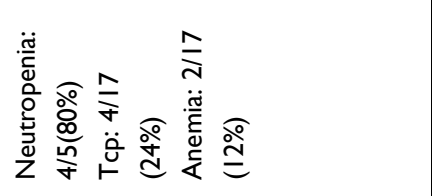 & 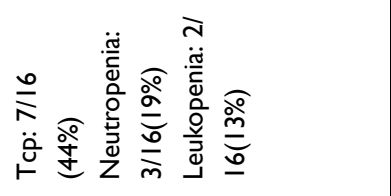 & 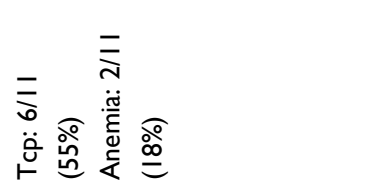 \\
\hline 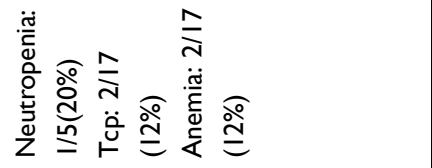 & & \\
\hline 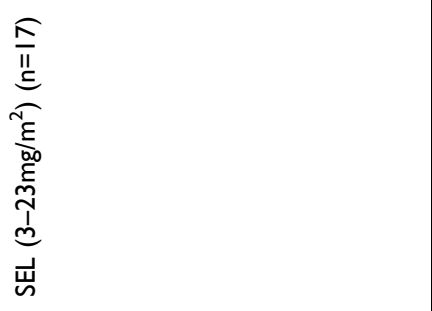 & 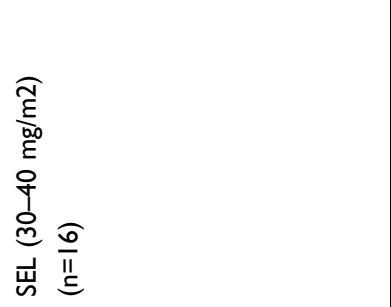 & 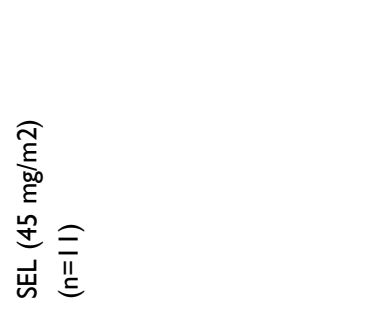 \\
\hline \multicolumn{3}{|l|}{ 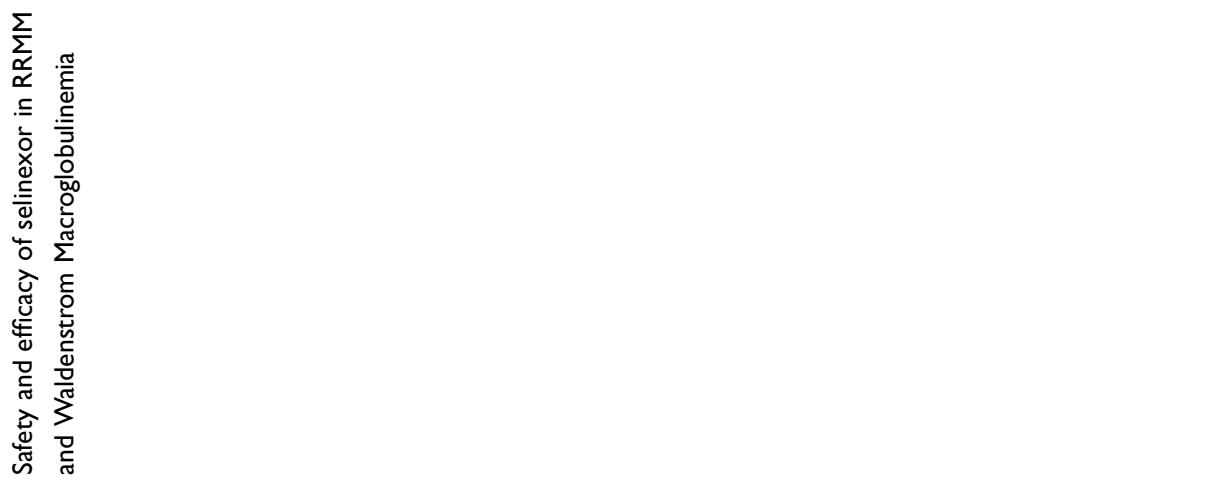 } \\
\hline 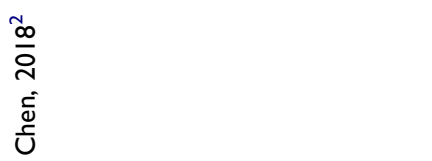 & & \\
\hline
\end{tabular}




\begin{tabular}{|c|c|c|c|c|}
\hline & 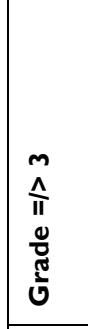 & 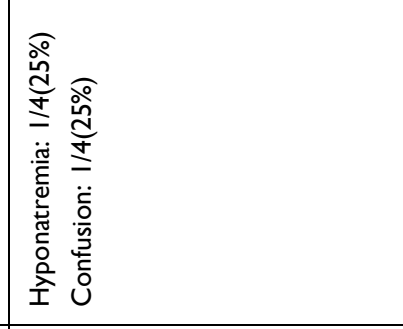 & 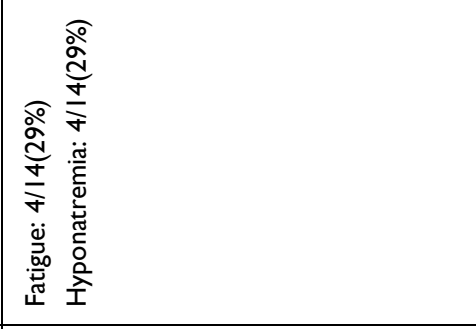 & 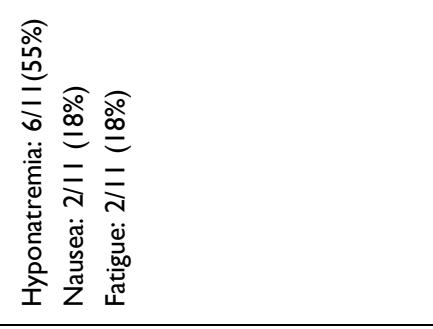 \\
\hline 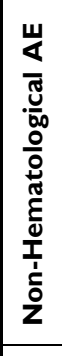 & 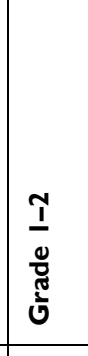 & 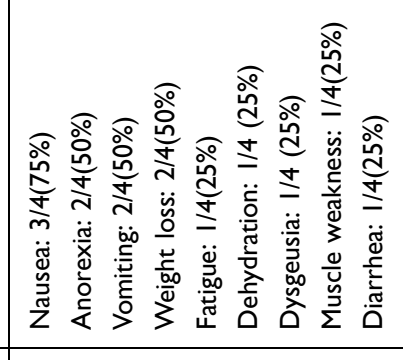 & 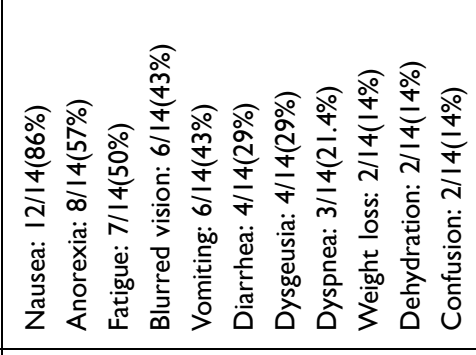 & 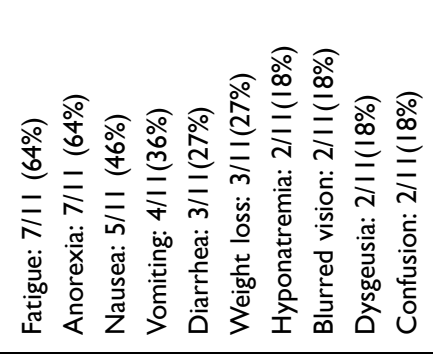 \\
\hline$\underset{\longleftarrow}{\stackrel{\mathrm{U}}{\alpha}}$ & $\begin{array}{l}m \\
\hat{\Lambda} \\
0 \\
\tilde{g} \\
\tilde{g} \\
0\end{array}$ & 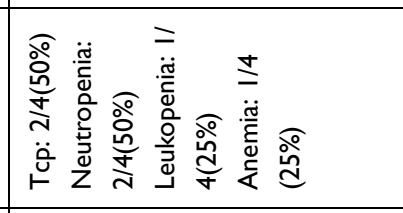 & 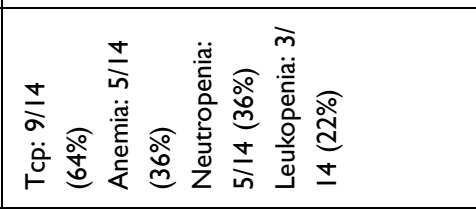 & 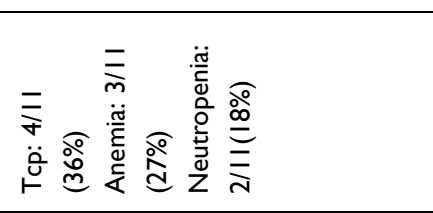 \\
\hline 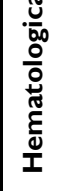 & 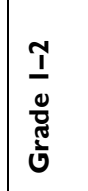 & 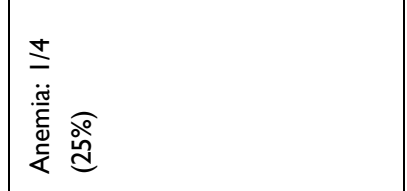 & & 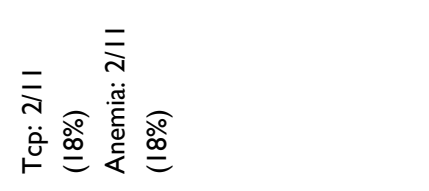 \\
\hline 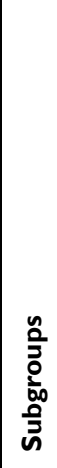 & & 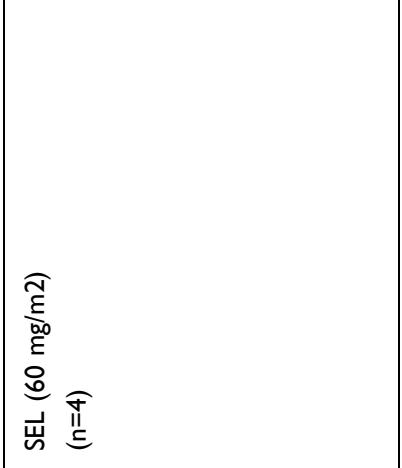 & 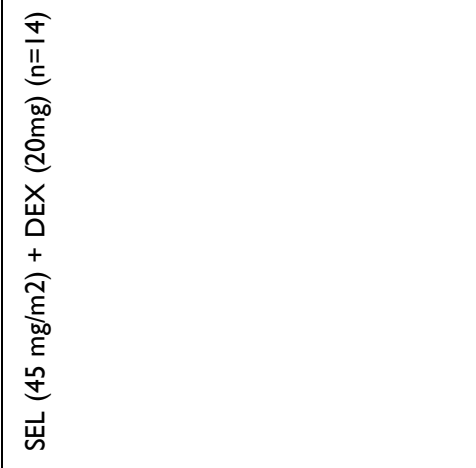 & 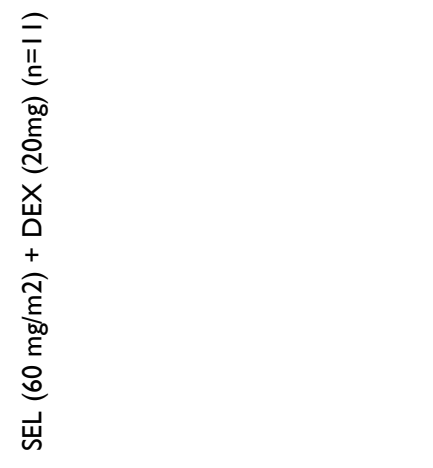 \\
\hline \multicolumn{5}{|l|}{$\frac{0}{2}$} \\
\hline & & & & \\
\hline
\end{tabular}




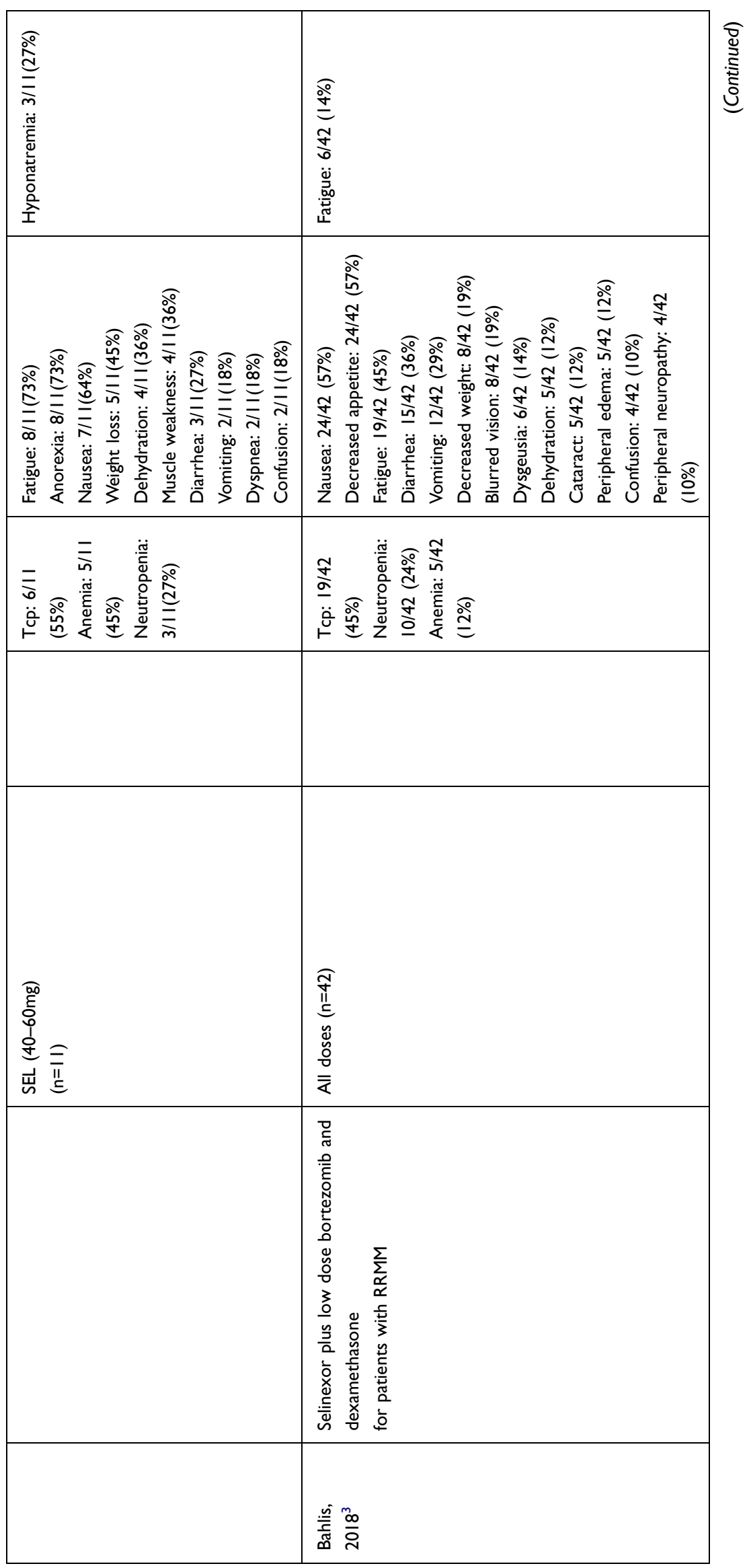




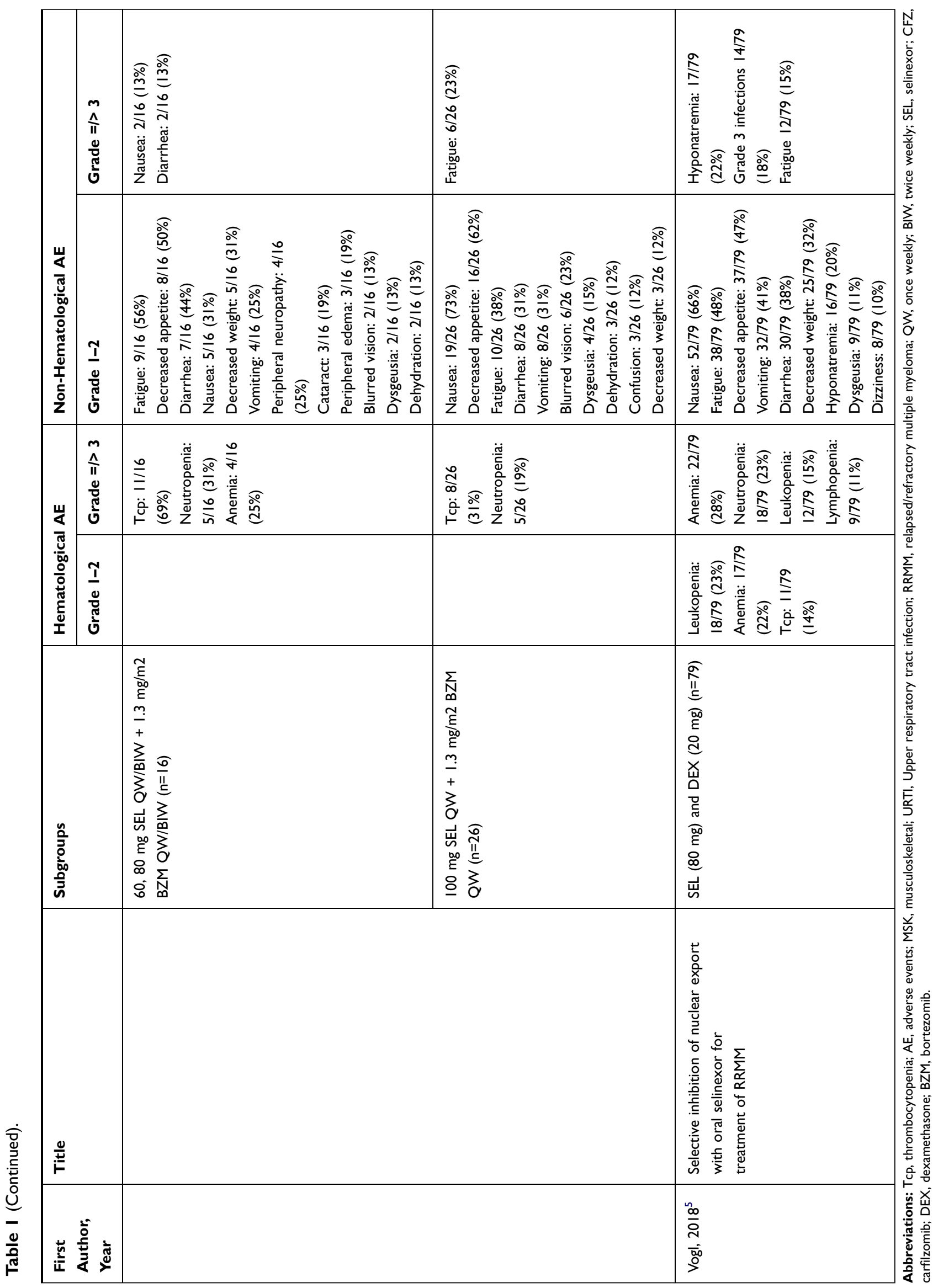


sepsis $(n=12)$, bacteremia $(n=4))$, fever with/without neutropenia $(\mathrm{n}=14), \quad$ encephalopathy/delirium/confusion $(\mathrm{n}=11)$, anemia $(\mathrm{n}=6)$, hyponatremia $(\mathrm{n}=6)$, dehydration $(n=6)$, renal failure $(n=4)$, nausea/vomiting $(n=4)$, thrombocytopenia $(n=4)$, elevated LFTs $(n=2)$, intracranial hemorrhage $(\mathrm{ICH}) \quad(\mathrm{n}=2)$ and GI bleeding $(\mathrm{n}=1))^{2,5,6}$ SAEs due to Sel-Dexa-Bort were febrile neutropenia $(\mathrm{n}=2)$, full-thickness macular hole in eye $(\mathrm{n}=1)$, and pulmonary embolism $(n=1){ }^{3}$ Sel-Dexa-Carf use resulted in infections more commonly $(\mathrm{n}=7)$ as SAEs, GI bleeding ( $\mathrm{n}$ $=1$; unrelated to treatment), syncope $(\mathrm{n}=1)$, thromboembolism $(\mathrm{n}=1)$, pain related to progressive disease $(\mathrm{n}=1)$ and systolic heart failure $(\mathrm{n}=1) .^{21}$

\section{Management of Selinexor Toxicity Hematologic Toxicity}

Thrombocytopenia, the primary hematological toxicity of Sel, occurs via inhibition of thrombopoietin (TPO)-signaling in the megakaryocyte maturation phase and can be managed with the use of TPO agonists (eltrombopag or romiplostim), platelet infusions, and drug holidays. Those with baseline thrombocytopenia are more prone to develop high-grade thrombocytopenia thereby predisposing them though rarely, to life-threatening bleeding events such as ICH or GI bleeding. ${ }^{2,6}$ Therefore, Sel needs to be avoided unless the platelet count is $\geq 50,000 / \mathrm{mm}$. ${ }^{3,6}$ On a similar note, patients who received platelet infusion within one week or TPO agents within 2 weeks prior to the first dose of Sel should not be administered Sel; those patients were excluded from the STORM trial part 2. Both in-vivo and in-vitro studies affirm that Sel-mediated thrombocytopenia is reversible with TPO-agonists ensuring that Sel has been washed out and there is no more ongoing Sel use. Otherwise, TPO-agents get antagonized by the TPOblocking mechanism of Sel causing ongoing thrombocytopenia. ${ }^{20}$ There are no strict guidelines about the TPO-agents' use in Sel toxicity and their use is solely at the discretion of treating hematologists. In the BOSTON trial where TPO-agents were used in $18 \%$ of patients with thrombocytopenia, the events of dose reductions or interruptions were significantly reduced. ${ }^{9}$ Sel-induced thrombocytopenia occurs in a dose-dependent fashion; one study looked at platelet drop at day 29 with different Sel doses and found evidence of less thrombocytopenia with its lower doses $(50-70 \mathrm{mg})(\mathrm{n}=36)$ vs higher doses $>100 \mathrm{mg}$ biweekly $(\mathrm{n}=28)$. The interruption of Sel dose for 8-21 days resulted in improvement in G-4 thrombocytopenia. ${ }^{20}$ Those who are receiving FDA approved dose of Sel and develop G-4 thrombocytopenia without bleeding should stop taking Sel until at least G-3. When at G-3, Sel dose needs to be reduced from $80 \mathrm{mg}$ twice-weekly ( $\sim 160 \mathrm{mg} /$ week) to $100 \mathrm{mg}$ once weekly until thrombocytopenia improves to G-2. Following this, Sel can be resumed in two divided doses per week (total $100 \mathrm{mg} /$ week), ie, $60 \mathrm{mg}, 40 \mathrm{mg}^{6}$

Adequate hematopoietic functions such as hemoglobin $>8 \mathrm{gm} / \mathrm{dl}$ and absolute neutrophils $>1000 / \mathrm{mm}^{3}$ should be ensured before Sel treatment, preferably in the absence of recent blood transfusions, erythropoietin (EPO) analogues or colony-stimulating factors (CSF). For G-3/4 anemia and neutropenia, Sel needs to be interrupted (counts can be boosted with EPO and CSF analogues per the discretion of the hematologist) as well until toxicity improves to G-2 and then Sel can be resumed at $60 \mathrm{mg}$ twice-weekly. As it is critical to modify the Sel treatment with respect to hematologic toxicity, the most important aspect of managing its toxicity is to monitor blood cell counts ideally before each dose of Sel so that the subsequent dose could be modified. However, given twiceweekly dosing of oral Sel, performing blood counts twice weekly might appear cumbersome which needs to be balanced with the clinical utility of these labs. Therefore, we recommend checking complete blood counts at least once-weekly in the first two cycles of Sel as a majority of these AEs require treatment modifications during this timeframe. Venous thromboembolism $(5 \%$ of the patients in one study), requires anticoagulation. ${ }^{21}$

\section{Gastrointestinal Toxicity}

GI toxicity such as nausea, anorexia/decreased appetite, vomiting, diarrhea, and weight loss are usually centrally mediated and though low-grade, can limit the tolerability of Sel. ${ }^{2}$ However, the addition of Dexa and the use of prophylactic antiemetics have improved its tolerance. ${ }^{2}$ Most of the GI AEs, particularly vomiting are usually severe in the first 2 weeks and may decrease over time. Antiemetic use has been reported in $89-100 \%$ of the patients receiving Sel and many patients might need two (14-33\%) or three antiemetics $(5 \%))^{3,5,6}$ For nausea/ vomiting, $8 \mathrm{mg}$ of ondansetron or equivalent antiemetics such as prochlorperazine, granisetron can be used before the first dose of Sel, and then ondansetron $8 \mathrm{mg}$ should be given as needed twice daily or thrice daily at least for 2 days. ${ }^{5,6}$ Those with persistent nausea despite ondansetron or equivalent can be given olanzapine and neurokinin-1 receptor blockers such as aprepitant and rolapitant. ${ }^{5,22}$ 
In STORM trial part 1, eight doses of Sel were compared with six doses of Sel in a 28-day cycle, the rate of nausea was $82 \%$ vs $69 \%$, respectively. ${ }^{5}$ Sel should be interrupted in case of G-3 nausea until it improves to G-2 and then Sel can be resumed at $60 \mathrm{mg}$ twice-weekly dosing. ${ }^{6} \mathrm{GI}$ toxicity is one of the most common causes of Sel termination. In one study, the treatment was terminated due to GI or constitutional AEs in $5 / 8$ patients. $^{23}$ Prophylactic antiemetics can successfully avoid interruptions, dose reductions, or treatment terminations. It is of note that the once-weekly maximal dose of Sel of $100 \mathrm{mg}$ along with the once-weekly Bort did not result in G-3/4 nausea, vomiting, or anorexia and was well tolerated with prophylactic antiemetics. ${ }^{3}$

Anorexia and weight loss in cancer patients receiving Sel can be multifactorial and result from both chemotherapy and underlying malignancy itself. The use of appetite stimulants in addition to low-dose Dexa such as dronabinol, metoclopramide, and megestrol may improve appetite and cause modest weight gain. ${ }^{3,24}$ One randomized controlled trial comparing dronabinol with megestrol reported megestrol to be superior compared to dronabinol both for improving the appetite ( $75 \%$ vs $49 \%$ ) and causing weight gain $(11 \%$ vs $3 \%)$. The study found no difference when dronabinol-megestrol combination was compared to megestrol alone. ${ }^{25}$ In a study by Jakubowiak et al., 100\% of patients $(\mathrm{n}=21)$ received prophylactic megestrol acetate (160-400 mg daily) and 5-HT3 antagonist but 29\% $(\mathrm{n}=6)$ of patients remained anorexic and $5 \%(\mathrm{n}=1)$ patients experienced ongoing weight loss. The combination of antiemetics, however, was more effective in managing treatment interruptions since none $(\mathrm{n}=0 / 21)$ of the patients required treatment discontinuations due to GI AEs. ${ }^{21}$ Another common AE of Sel is G-1/2 diarrhea that might require antidiarrheals. G-3/4 diarrhea was reported in $10 \%$ of patients by Jakubowiak et $\mathrm{al}^{21}(\mathrm{n}=2 / 21)$ and even less commonly $(5-7 \%)$ by other investigators. ${ }^{5,23,26}$ For $\geq \mathrm{G} 2$ diarrhea, Sel should be interrupted and resume when resolved to G1 but at $60 \mathrm{mg}$ twice-weekly dose. One unrelated meta-analysis of eight randomized controlled trials found octreotide to be effective for severe cases of chemotherapy-induced diarrhea when compared to placebo (69\% vs 54\%). ${ }^{27,28}$ Dysgeusia reported in $10-17 \%$ of the patients in Sel studies is common with many other therapies but lacks evidence-based treatment strategies. ${ }^{29}$

\section{Renal Toxicity and Electrolyte Derangements}

Dehydration and AKI are less common G-3/4 AEs with Sel and have a favorable outcome. These can be managed with outpatient fluid resuscitation or inpatient care depending upon severity. ${ }^{30}$ Thus, far only one case of irreversible renal failure has been reported leading to treatment discontinuation. ${ }^{6}$ G-3/4 hyponatremia is also common with Sel and should be managed with Sel interruption and dose reductions. Sel should be resumed at $60 \mathrm{mg}$ twice weekly when the hyponatremia is at least G1 or resolved. Hyponatremia, even though G-3, is mostly asymptomatic and needs sodium replacement along with frequent lab monitoring. In the STORM trial part 1 , only $6 \%$ of patients required salt tablets as compared to $22 \%$ of patients diagnosed with hyponatremia. ${ }^{5}$ Chen et al. attributed a number of cases of delirium to hyponatremia. Delirium usually requires supportive care and correction of metabolic derangements such as hyponatremia. ${ }^{2}$

\section{Dose Adjustments}

Early intervention with supportive care prevents the need for dose reduction and interruption. Treatment holidays and dose reductions were required in $52 \%$ and $37 \%$ of the study population in STORM part 1 and resulted in significantly less treatment termination (18\%). This study had only three patients who received a higher dose of Sel $100 \mathrm{mg}$ twice-weekly with all three patients requiring drug holidays or dose reduction. ${ }^{5}$ In the STORM part 2, $80 \%$ of patients required dose modifications or holidays and the majority of those events occurred in the first 2 cycles, demanding an aggressive prophylactic treatment, and monitoring needs in the initial cycles. ${ }^{6}$ About $17.2 \%$ of patients discontinued treatment due to treatment-related AEs. Bahlis et al. studied various dosing regimens for Bort and Sel in different combinations. There was no significant increase in G-3/4 AEs with Sel $100 \mathrm{mg}$ weekly compared to $60 \mathrm{mg}$ or $80 \mathrm{mg}$ weekly regimen. ${ }^{3}$ Jakubowiak et al reported $80 \%$ of patients receiving Sel needed a change in dosage or holiday from therapy but only $18 \%$ discontinued treatment due to AEs and $10 \%$ mortality $(n=12 / 123)$ was attributed to major AEs. The rest recovered with conservative management. ${ }^{21}$ Dose/ treatment modifications to minimize adverse events are summarized in Table 2.

\section{Toxicity Profile of Belantamab Mafodotin}

Trudel et al. reported the first-in-human Phase I trial (DREAMM-1) of belantamab mafodotin (belamaf) which included a dose-escalation phase (part $1, \mathrm{n}=38$ ) and a doseexpansion phase (part 2, $n=35$ ). Based on the results of part $1,3.4 \mathrm{mg} / \mathrm{kg}$ was the recommended dose in part $2 .^{16,17}$ 
Table 2 Adverse Events Leading to Modifications in Treatment Plan in Selinexor Studies

\begin{tabular}{|c|c|c|c|}
\hline & Treatment Holiday/Interruption & Dose Reduction & Treatment Termination \\
\hline Vogl et $\mathrm{al}^{5}$ & $52 \%(n=4 I / 79)$ & $37 \%(n=29 / 79)$ & $18 \%(n=14 / 79)$ \\
\hline Bahlis et $\mathrm{al}^{3}$ & & $50 \%(n=21 / 42)$ & $19 \%(n=8 / 42)$ \\
\hline 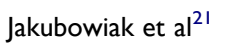 & $80 \%(n=|7 / 2|)$ & $62 \%(n=|3 / 2|)$ & $10 \%(n=2 / 21)$ \\
\hline Chen et $\mathrm{al}^{2}$ & & & $31 \%(n=26 / 84)$ \\
\hline
\end{tabular}

Lonial et al conducted a phase II study (DREAMM-2) with two dosing cohorts in 196 RRMM patients. Ninetyseven patients were treated with $2.5 \mathrm{mg} / \mathrm{kg}$ and 99 patients with $3.4 \mathrm{mg} / \mathrm{kg}$ of belamaf. ${ }^{15}$ In part 1 of the DREAMM-1, no dose-limiting AEs were reported and there was no maximum tolerated dose. The most common G-3/4 AEs were thrombocytopenia [13/38 (34\%)] and anemia [6/38 $(16 \%)]$. In part 2 of DREAMM-1, G-3/4 AEs were seen in $28 / 35(80 \%)$ patients, the most common being thrombocytopenia [12/35 (34\%)] and anemia [5/35 (14\%)]. SAEs were seen in $40 \%$ of patients, the most common of which were infusion-related reaction (IRR) $(\mathrm{n}=2)$ and lung infection $(\mathrm{n}=2)$. Five patients had drug-related SAEs including IRR $(\mathrm{n}=2), \operatorname{ICH}(\mathrm{n}=1)$, lung infection $(\mathrm{n}=1)$ and pericardial effusion $(\mathrm{n}=1){ }^{17}$

In the DREAMM-2, the most common G-3/4 AEs were keratopathy seen in 26/95 (27\%) patients in the 2.5 $\mathrm{mg} / \mathrm{kg}$ cohort and 34/99 (34\%) patients in the $3.4 \mathrm{mg} / \mathrm{kg}$ cohort. Thrombocytopenia was seen in 19/95 (20\%) and $33 / 99$ (33\%), respectively, for $2.5 \mathrm{mg} / \mathrm{kg}$ and $3.4 \mathrm{mg} / \mathrm{kg}$ cohorts and anemia in 19/95 (20\%) and 25/99 (25\%) respectively. Among those who received prophylaxis for IRR, $8 / 22$ (2.5 mg/kg cohort) and 6/27 (3.4 mg/kg cohort) patients developed IRR. One patient in the $2.5 \mathrm{mg} / \mathrm{kg}$ cohort discontinued treatment due to G-3 IRR. ${ }^{15}$ In part 1 of the DREAMM-1, dose reduction was required in $1 / 3$ (33\%) patients receiving $1.92 \mathrm{mg} / \mathrm{kg}, 1 / 8$ (13\%) patients receiving $2.50 \mathrm{mg} / \mathrm{kg}, 3 / 3(100 \%)$ patients receiving 3.40 $\mathrm{mg} / \mathrm{kg}$ and $5 / 6(83 \%)$ in $4.6 \mathrm{mg} / \mathrm{kg}$ dose. Moreover, $1 / 4$ (25\%) patients receiving $1.92 \mathrm{mg} / \mathrm{kg}$ and $2 / 6(33 \%)$ patients receiving $4.6 \mathrm{mg} / \mathrm{kg}$ dose in part 1 discontinued treatment due to AEs which included limbal cell defect, foreign body sensation in eyes plus thrombocytopenia, and hypercalcemia. The blurring of vision (40\%) was the most common cause of interruption or delay in belamaf therapy in the DREAMM-1. ${ }^{17}$ In part 2 of DREAMM-1, belamaf related AEs include IRR, thrombocytopenia, and corneal events. Two patients $(6 \%)$ discontinued treatment and 7 $(20 \%)$ required dose reduction/delays because of thrombocytopenia. AEs led to dose reduction in 23/45 (66\%) and dose interruption/delay in 25/45 (71\%) patients. $^{17}$ In DREAMM-2, 93/95 (98\%) patients in $2.5 \mathrm{mg} / \mathrm{kg}$ cohort and $99 / 99(100 \%)$ patients in $3.4 \mathrm{mg} / \mathrm{kg}$ cohort had at least one AE. AEs led to dose delays in $54 \%(2.5 \mathrm{mg} / \mathrm{kg}$ cohort) and $62 \%$ (in $3.4 \mathrm{mg} / \mathrm{kg}$ cohort) patients while dose reduction was required in $29 \%(2.5 \mathrm{mg} / \mathrm{kg}$ cohort $)$ and $41 \%$ (3.4 mg/kg cohort) patients. About $8 \%$ ( $2.5 \mathrm{mg} / \mathrm{kg}$ cohort) and $10 \%(3.4 \mathrm{mg} / \mathrm{kg}$ cohort) patients permanently discontinued the treatment due to AEs in DREAMM-2 the most common of which being keratopathy seen in $1(2.5 \mathrm{mg} / \mathrm{kg}$ cohort) and $3\left(3.4 \mathrm{mg} / \mathrm{kg}\right.$ cohort) patients. ${ }^{15}$ One death occurred in part 1 of DREAMM-1 study which was attributed to disease progression. Three deaths occurred in part 2 owing to disease progression. No treatment-related deaths were reported in DREAMM- $1 .{ }^{17} \mathrm{~A}$ total of two potentially treatment-related deaths were reported in DREAMM-2, one due to sepsis in the $2.5 \mathrm{mg} / \mathrm{kg}$ cohort and one due to hemophagocytic lymphohistiocytosis in the $3.4 \mathrm{mg} / \mathrm{kg}$ cohort. ${ }^{15}$

In part 1 of DREAMM-1, the frequency of G-3-4 corneal AEs increased with the increased dose of the drug. Corneal AEs were reported in 20/38 (53\%) patients, most of which were mild G-1/2 seen in 18/38 (47\%) but it resulted in treatment discontinuation in two patients. In part 2 of DREAMM-1, corneal events were seen in 22/35 (63\%) patients comprising of mild-moderate (G-1/2) in 19 and G-3 in 3 (keratitis in 1, eye pain in 1, and dry eye in 1) patients. The median time to onset of corneal events was 23 days (range: 1-84 days) while the median duration of patients with a resolution date was 30 days (range: 5-224 days). Thirty-one (89\%) patients had corneal findings on the ophthalmic examination which included superficial punctate keratitis 27/35 (77\%), epithelial edema 22 (63\%), stromal edema $5(14 \%)$, and opacities 8 (23\%). No patients discontinued treatment in part 2 due to corneal AEs. ${ }^{17}$ In DREAMM-2, keratopathy was the most common cause of permanent treatment discontinuation with $1 \%(2.5 \mathrm{mg} / \mathrm{kg}$ cohort $)$ and $3 \%(3.4 \mathrm{mg} / \mathrm{kg}$ cohort $)$. It led to dose reduction in $23 \%(2.5 \mathrm{mg} / \mathrm{kg}$ cohort $)$ and $27 \%$ $(3.4 \mathrm{mg} / \mathrm{kg}$ cohort $)$ and dose delays in $27 \%(2.5 \mathrm{mg} / \mathrm{kg}$ 
cohort) and 48\% (3.4 mg/kg cohort) patients. The most common reported corneal symptoms were blurred vision and dry eye in two patients without keratopathy. In the ocular sub-study ( $\mathrm{n}=30 ; 17$ patients in $2.5 \mathrm{mg} / \mathrm{kg}$ cohort and 12 patients in $3.4 \mathrm{mg} / \mathrm{kg}$ cohort), G-3 AEs were reported in $29 \%(2.5 \mathrm{mg} / \mathrm{kg}$ cohort $)$ and $42 \%(3.4 \mathrm{mg} / \mathrm{kg}$ cohort $)$ in treated eye and $18 \%(2.5 \mathrm{mg} / \mathrm{kg}$ cohort $)$ and $50 \%$ ( $3.4 \mathrm{mg} / \mathrm{kg}$ cohort) in untreated eye. ${ }^{15}$ The toxicity profile of belamaf has been summarized in Table 3 .

\section{Management of Toxicity of Belantamab Mafodotin}

Cytotoxic payload and linker instability are postulated to cause the ocular toxicity associated with ADC. ${ }^{31}$ Previously many clinical trials ${ }^{31-33}$ of refractory hematologic malignancies have used MMAF cytotoxin and maleimidocaproyl linker and have reported similar ocular toxicity as reported in DREAMM-1 and DREAMM-2 trials due to belamaf. Ophthalmic steroid drops in DREAMM-1 were used to mitigate the ocular toxicity given the established side effects of MMAF. ${ }^{16}$ However, ocular toxicity (blurring of vision, eye pain, and dryness, keratitis, and photophobia) still occurred, especially with the increasing doses of the drug. ${ }^{17}$ Permanent discontinuations due to corneal events were rare in this trial and the majority of these AEs were successfully managed with dose reductions, interruptions, or delays. About $50 \%$ of individuals with corneal events showed a resolution within about 35 days. ${ }^{17}$ On follow-up interviews of 17 patients from the second part of DREAMM- 1 trial at the end of treatment, $76 \%$ of patients had reported of blurred vision while on treatment but $62 \%$ either had resolution or ongoing improvement in the complaint. The majority of those who participated in this interview never considered treatment discontinuation. ${ }^{34}$ Ophthalmic evaluation while on belamaf plays a crucial role in the early detection of keratitis, epithelial and stromal edema. Therefore, serial ophthalmic evaluation at baseline and before subsequent doses have a critical role as a mitigation strategy and may prompt treatment adjustments. Popat et al reported a case series of 5 patients from the DREAMM-1 trial and shared experience from their center at a median follow-up of 32.6 months. When corneal AEs occurred, they increased the frequency of topical steroids (prednisolone eye drops 1-2 drops up to four times a day), used preservative-free artificial tears (such as artificial tears 1-2 drops twice a day as needed), and interrupted the next dose (median 14 days, range: 7-98 days). These patients developed increased intraocular pressure, infection, and secondary cataract formation given the excessive use of topical steroids and required topical antibiotics and cataract extractions. Therefore, Popat et al. recommended against the long-term use of topical steroids and proposed dose modifications or interruptions as the main strategy to deal with corneal side effects. ${ }^{35}$

DREAMM-2 trial investigators made ophthalmic evaluations a part of their protocol. The reports of changes in visual acuity were also subject to strict follow-up. Those patients with visual changes experienced ultimate resolution and none of them had permanent vision loss. An ocular substudy, part of the DREAMM-2, verified no role of topical steroids in preventing corneal side effects. Dose reductions or delays were the most effective strategies. DREAMM-2 trial, therefore, recommends $25 \%$ dose reduction if G-2 corneal events have been experienced and interruption or delay of the dose if G-3/4 corneal events have been experienced. The dose should be delayed until the corneal event is improved to G-2 and then belamaf with a $25 \%$ reduced dose should be given. In the United States, belamaf has been available since August 2020 under a Risk Evaluation and Mitigation Strategy (REMS) given ocular toxicity, called BLENREP REMS. ${ }^{13}$ Dosage modifications of belamaf in RRMM can be made based on the Keratopathy and Visual Acuity (KVA) scale documented in the prescribing information of BLENREP (Table 4). ${ }^{13,19,36}$ This scale was developed by GlaxoSmithKline (GSK) upon the recommendation of the FDA.

In DREAMM-1, onset of thrombocytopenia was observed for $50 \%$ at 7.5 days and $50 \%$ had resolution after 8 days of onset. Only $6 \%$ had discontinuation of therapy due to thrombocytopenia. These side effects can be managed with modification in the treatment plan. ${ }^{16,17}$ However, in DREAMM-2, thrombocytopenia was considered self-limiting. A total of 22 patients (11\%) reported bleeding of G-2 or worse. ${ }^{15}$ Serious infections such as pneumonia or lung infection might require dose interruptions or delays.

\section{Discussion}

Despite advancements in MM treatment over decades, with many active drugs and the use of hematopoietic stem cell transplantation/autologous stem cell transplantation, it remains incurable, and invariably patients with MM relapse and require therapies for the treatment of relapse. ${ }^{37}$ During the course of illness, a considerable 


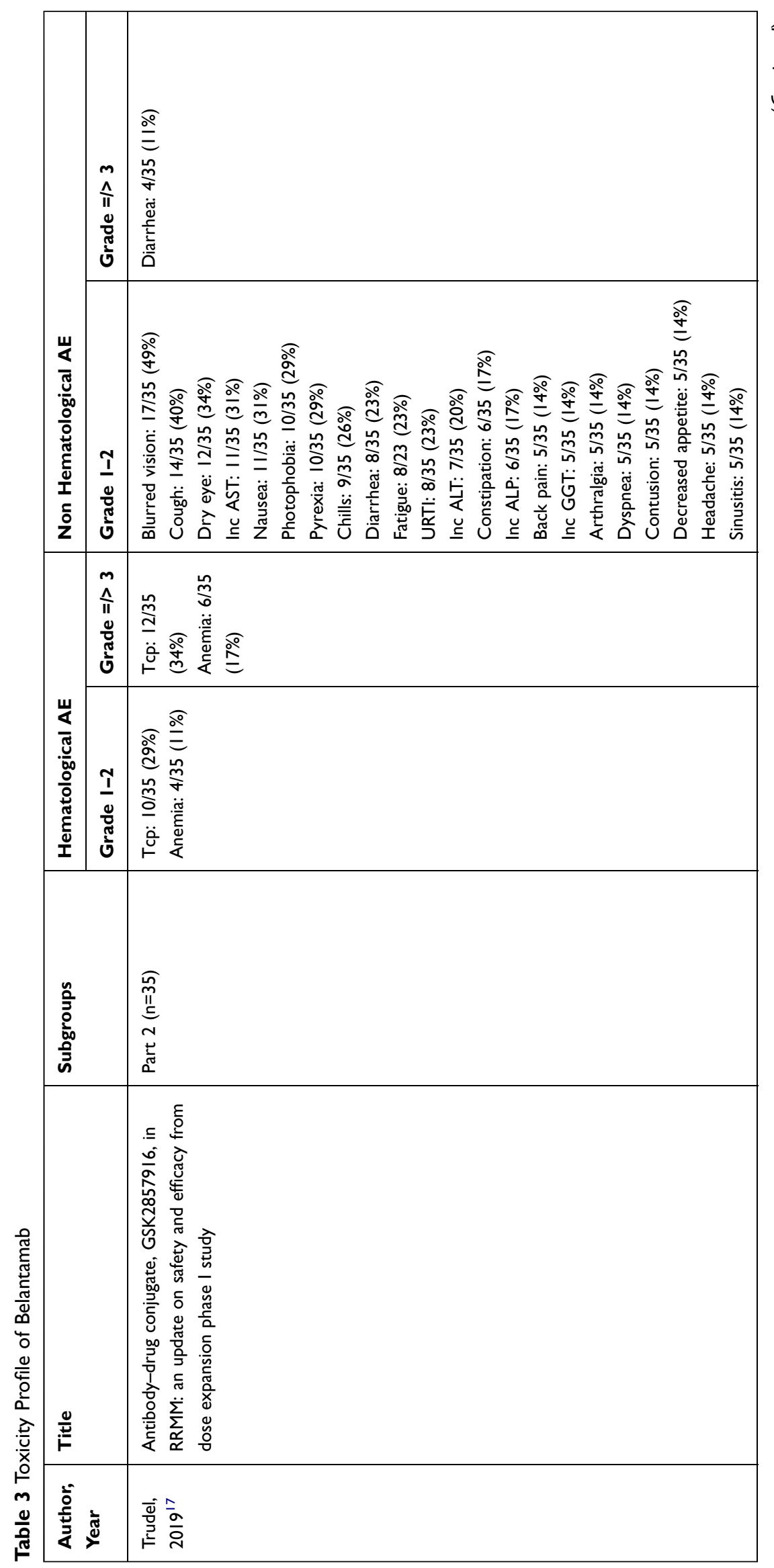




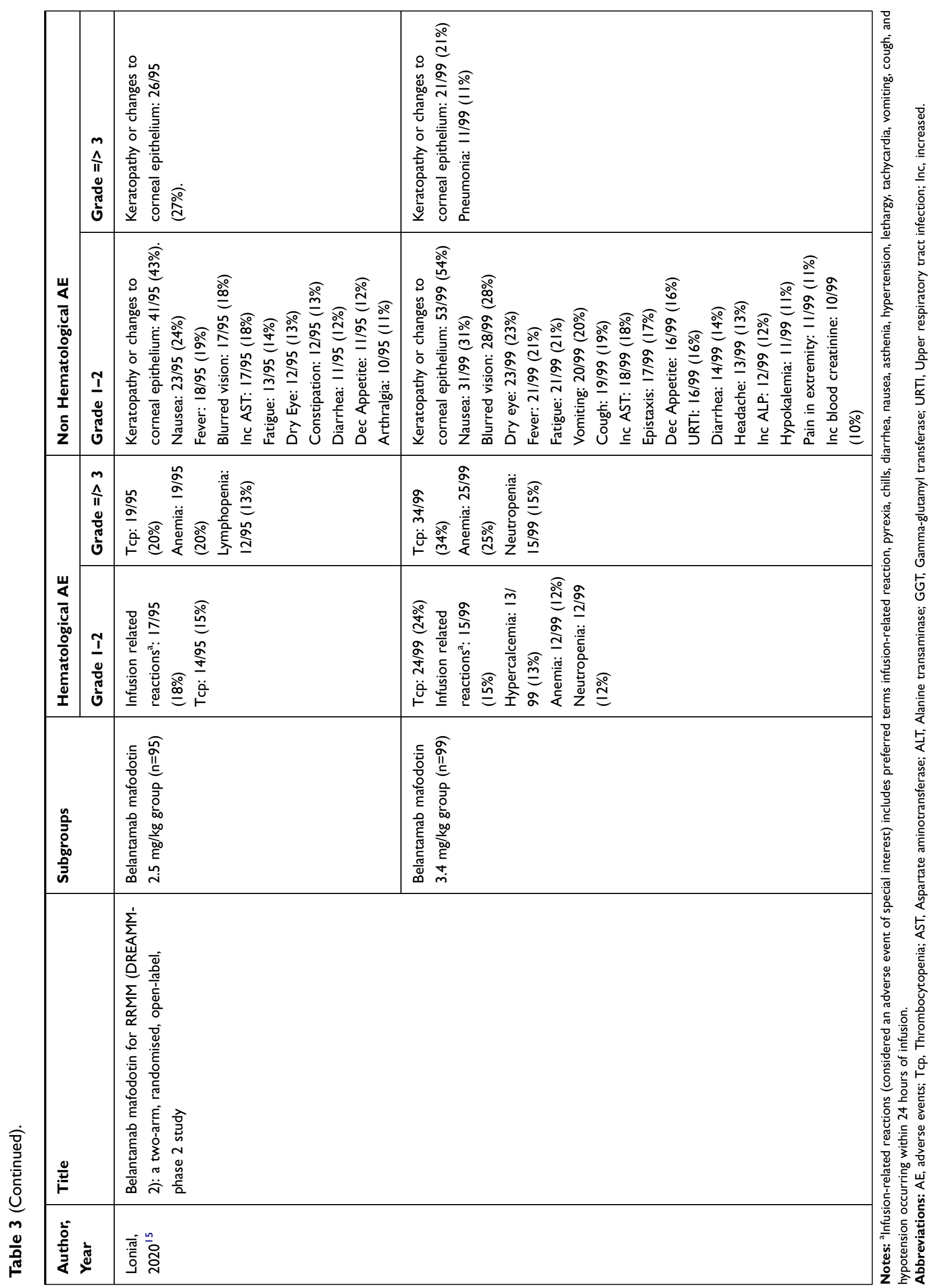


Table 4 Management of Ocular Toxicity of Belamaf

\begin{tabular}{|l|l|l|}
\hline Severity & Extent of Vision Loss & Treatment Recommendations \\
\hline Grade I & $\begin{array}{l}\text { One line decline of best corrected visual acuity from baseline on Snellen Visual Acuity } \\
\text { chart OR mild superficial keratopathy on corneal examination. }\end{array}$ & $\begin{array}{l}\text { Treatment to be continued at current dose } \\
\text { without any modification }\end{array}$ \\
\hline Grade 2 & $\begin{array}{l}2 \text { or } 3 \text { lines decline of best corrected visual acuity from baseline on visual acuity chart } \\
\text { (not worse than 20/200) OR moderate superficial keratopathy on corneal } \\
\text { examination. }\end{array}$ & $\begin{array}{l}\text { Hold belamaf until improves to grade I and } \\
\text { resume same dose afterwards }\end{array}$ \\
\hline Grade 3 & $\begin{array}{l}\text { More than } 3 \text { lines decline of best corrected visual acuity from baseline on visual acuity } \\
\text { chart (not worse than 20/200) OR severe superficial keratopathy on corneal } \\
\text { examination. }\end{array}$ & $\begin{array}{l}\text { Hold belamaf until improves to grade I and } \\
\text { then resume 25\% reduced dose }\end{array}$ \\
\hline Grade 4 & $\begin{array}{l}\text { Severely reduced vision (visual acuity worse than 20/200 on Snellen Visual Acuity } \\
\text { chart) OR corneal epithelial defects on corneal examination. }\end{array}$ & $\begin{array}{l}\text { Belamaf treatment termination with urgent } \\
\text { ophthomology consult }\end{array}$ \\
\hline
\end{tabular}

number of patients develop a refractory disease to three classes of commonly used drugs (PIs, IMiDs, and monoclonal antibodies). Overall survival in three-class, quad, or penta refractory disease is short. ${ }^{6}$ MAMMOTH study reported outcomes of MM patients who were refractory to anti-CD38-monoclonal antibody and other agents. The median overall survival after anti-CD38 antibodies refractoriness was 8.6 months, 11.2 months in patients who were not simultaneously refractory to one IMiD and one PI, and 5.6 months in patients who were refractory to anti-CD-38 antibodies, two PIs, and two IMiDs (penta-refractory). ${ }^{38}$ After multiple lines of treatment exposures, at the time of relapses, such patients have underlying marrow suppression and cumulative toxicities. Therefore, it becomes essential that they maintain a good quality of life while we use newly approved drugs such as Sel and belamaf.

After multiple prior lines of therapy, the selection of the appropriate next line of therapy is crucial in the context of prior toxicities, including profound thrombocytopenia. Sel at recommended doses (80 $\mathrm{mg}$ twice weekly) may not be an appropriate treatment choice for such patients due to the risk of ICH and GI bleeding depending on the severity of thrombocytopenia and should be avoided unless the platelet count is at least 50,000 . However, thrombocytopenia is reversible with drug interruption and the use of TPO agents. ${ }^{39}$ For severe thrombocytopenia, platelet transfusions have been shown to be effective in quickly increasing the platelet levels. TPO agonists (romiplostim or eltrombopag) can be used to increase platelet counts over two to 3 weeks while continuing the treatment with selinexor. TPO agonists should be used when platelet counts fall below $25,000 / \mathrm{mm}^{3}$ until the count rises to $\geq 50,000 /$ $\mathrm{mm}^{3}{ }^{40}$ Frequent monitoring of platelet counts during Sel treatment is highly recommended. Sel should be interrupted for G4 thrombocytopenia and the dose should be reduced for G3/2 thrombocytopenia. Any life-threatening bleeding event history such as $\mathrm{ICH}$ should be carefully weighed against the re-induction of treatment and its benefits and reintroduction should be avoided if at all possible.

When considering belamaf, it is of utmost importance that the treating hematologist is aware of its ocular toxicity and its management strategies as it may have dire visual consequences. Belamaf is currently available under REMS program that requires special certification for prescribers. About $76 \%$ of the patients in the DREAMM-1 reported some ocular complications. ${ }^{16}$ A baseline ophthalmic evaluation and proper documentation of any visual problems using a KVA scale should be performed. Following the baseline evaluation, findings should be documented before each dose to monitor any change and tailor treatment according to the findings. It is prudent for the treating hematologist to discuss ocular toxicity with the ophthalmologist and request findings based on the KVA scale as it is a relatively newer drug, and many ophthalmologists might have limited experience. The patient on belamaf should be strictly advised to use preservative-free eye drops four times a day. The documentation of the use of contact lenses should be made and, if possible, avoided as it may worsen the keratitis. The DREAMM-2 ocular substudy data did not demonstrate a clinical benefit of prophylactic topical steroids and therefore should be avoided. $^{15}$ Preferably a strategy of dose interruption and reductions based on the KVA scale should be employed in 
Table 5 Management of Toxicities of Selinexor and Belamaf

\begin{tabular}{|c|c|c|c|}
\hline Drug & Type of Toxicity & Nature of Toxicity & Management \\
\hline \multirow[t]{14}{*}{ Selinexor } & \multirow[t]{11}{*}{ Non-hematological } & Infection/pneumonia & $\begin{array}{l}\text { Antibiotics } \\
\text { Hospitalization for supportive care }\end{array}$ \\
\hline & & Fatigue $^{a}$ & Physical therapy \\
\hline & & Diarrhea $^{a}$ & $\begin{array}{l}\text { Loperamide } \\
\text { Diphenoxylate/atropine } \\
\text { Octreotide (severe or refractory) }\end{array}$ \\
\hline & & Hyponatremia $^{a}$ & Sodium replacement (normal saline or salt tablets) \\
\hline & & $\begin{array}{l}\text { Elevation of liver }{ }^{\mathrm{a}} \text { and } \\
\text { pancreatic enzymes }\end{array}$ & Watchful monitoring (transient only) \\
\hline & & Dehydration & Fluid resuscitation (infusion center vs inpatient) \\
\hline & & Nausea ${ }^{a} /$ Vomiting & $\begin{array}{l}\text { Antiemetics (Ondansetron, prochlorperazine, granisetron, } \\
\text { aprepitant) }\end{array}$ \\
\hline & & Anorexia/Weight loss ${ }^{a}$ & $\begin{array}{l}\text { Combine with dexamethasone } \\
\text { Dronabinol } \\
\text { Megestrol acetate } \\
\text { Metoclopramide }\end{array}$ \\
\hline & & Dysgeusia & Supportive \\
\hline & & Confusion & Correct underlying cause like hyponatremia \\
\hline & & Cataract & Surgical extraction \\
\hline & \multirow[t]{3}{*}{ Hematological } & Thrombocytopenia & $\begin{array}{l}\text { Dose reduction or interruptions } \\
\text { Treatment holidays } \\
\text { Platelet transfusion } \\
\text { Thrombopoietin receptor agonists }\end{array}$ \\
\hline & & Anemia $^{a}$ & Packed RBC Transfusion \\
\hline & & Neutropenia ${ }^{a}$ & Granulocyte Colony Stimulating Factor \\
\hline \multirow[t]{11}{*}{$\begin{array}{l}\text { Belantamab } \\
\text { mafodotin (Belamaf) }\end{array}$} & \multirow[t]{11}{*}{ Non-hematological } & Keratopathy & $\begin{array}{l}\text { Avoid use of ophthalmic steroid drops (risk of steroid-induced } \\
\text { glaucoma, cataract, and infection) }\end{array}$ \\
\hline & & Blurred Vision & Serial ophthalmic evaluations \\
\hline & & Visual acuity decline & $\begin{array}{l}\text { Use of keratopathy and visual acuity scale }(K V A) \text { to decide future } \\
\text { treatments of belamaf. }\end{array}$ \\
\hline & & Photophobia & Management of Ocular toxicity: see Table 3 \\
\hline & & Dry Eyes & Preservative free artificial tears \\
\hline & & Pyrexia/headache/arthralgia & Acetaminophen/lbuprofen \\
\hline & & Constipation & Laxatives \\
\hline & & Epistaxis & $\begin{array}{l}\text { Correct underlying thrombocytopenia if severe } \\
\text { Symptomatic management }\end{array}$ \\
\hline & & Acute kidney injury & Fluid resuscitation can be inpatient or infusion center \\
\hline & & Hypokalemia & Replace potassium orally (outpatient) or intravenous (inpatient) \\
\hline & & Upper respiratory infection & Antibiotics \\
\hline
\end{tabular}

(Continued) 
Table 5 (Continued).

\begin{tabular}{|c|c|c|c|}
\hline Drug & Type of Toxicity & Nature of Toxicity & Management \\
\hline & & Cough & Dextromethorphan \\
\hline & & Hypercalcemia & $\begin{array}{l}\mathrm{Ca}<12 \mathrm{mg} / \mathrm{dl}: \text { No treatment } \\
\mathrm{Ca} 12-14 \mathrm{mg} / \mathrm{dl}: \text { Normal saline and bisphosphonates } \\
\mathrm{Ca}>14 \mathrm{mg} / \mathrm{dl}: \text { Calcitonin or zoledronic acid in addition to normal } \\
\text { saline }\end{array}$ \\
\hline & & Infusion-related reactions ${ }^{\mathrm{b}}$ & $\begin{array}{l}\text { Premedication helpful. } \\
\text { Supportive care for symptoms }\end{array}$ \\
\hline & Hematological & Thrombocytopenia & $\begin{array}{l}\text { Platelet } 25,000 / \mathrm{mm}^{3} \text { to }<50,0000 / \mathrm{mm}^{3} \text { : Withhold and/or reduce } \\
\text { the dose } \\
\text { Platelet }<25,000 / \mathrm{mm}^{3} \text { : Withhold drug }\end{array}$ \\
\hline
\end{tabular}

Notes: aAdverse Events of belantamab as well. Management same as selinexor. ' ${ }^{b}$ nfusion-related reactions include a myriad of symptoms related to infusion such as pyrexia, chills, diarrhea, nausea, asthenia, hypertension, lethargy, tachycardia, vomiting, cough, and hypotension occurring within 24 hours of infusion.

Abbreviations: G, grade; RBC, red blood cell; $\mathrm{Ca}$, calcium.

Table 6 Ongoing Clinical Studies for Selinexor and Belantamab (Source: Clinicaltrials.gov)

\begin{tabular}{|c|c|c|c|}
\hline $\mathbf{S . N}$ & Title & Status & $\begin{array}{l}\text { NCT } \\
\text { Number }\end{array}$ \\
\hline I & $\begin{array}{l}\text { Selinexor Treatment for Multiple Myeloma Patients Who Are Refractory to Lenalidomide-containing } \\
\text { Therapy. }\end{array}$ & Recruiting & NCT045I9476 \\
\hline 2 & Selinexor (KPT-330) and Liposomal Doxorubicin For Relapsed and Refractory Multiple Myeloma & $\begin{array}{l}\text { Active, not } \\
\text { recruiting }\end{array}$ & NCT02I86834 \\
\hline 3 & $\begin{array}{l}\text { Selinexor Plus High-Dose Melphalan (HDM) Before Autologous Hematopoietic Cell Transplantation for } \\
\text { Multiple Myeloma }\end{array}$ & Recruiting & NCT02780609 \\
\hline 4 & $\begin{array}{l}\text { A Study of Selinexor Plus Low-dose Dexamethasone in Participants With Penta-refractory Multiple } \\
\text { Myeloma or Selinexor and Bortezomib Plus Low-dose Dexamethasone in Participants With Triple-class } \\
\text { Refractory Multiple Myeloma }\end{array}$ & Recruiting & NCT044I4475 \\
\hline 5 & $\begin{array}{l}\text { Selinexor, Carfilzomib, and Dexamethasone in Treating Patients With Relapsed or Refractory Multiple } \\
\text { Myeloma }\end{array}$ & Recruiting & NCT02199665 \\
\hline 6 & Bortezomib, Selinexor, and Dexamethasone in Patients With Multiple Myeloma & $\begin{array}{l}\text { Active, not } \\
\text { recruiting }\end{array}$ & NCT03II 0562 \\
\hline 7 & SELIBORDARA: Selinexor, Bortezomib and Daratumumab in Multiple Myeloma & Recruiting & NCT03589222 \\
\hline 8 & Selinexor and Backbone Treatments of Multiple Myeloma Patients & Recruiting & NCT02343042 \\
\hline 9 & $\begin{array}{l}\text { Selinexor, Pomalidomide, and Dexamethasone With or Without Carfilzomib for the Treatment of } \\
\text { Patients With Relapsed Refractory Multiple Myeloma, The SCOPE Trial }\end{array}$ & Recruiting & NCT04764942 \\
\hline 10 & A Study of Evaluating the Safety and Efficacy of ATG-0I0 in Relapsed Refractory Multiple Myeloma & Recruiting & NCT03944057 \\
\hline 11 & Myeloma-Developing Regimens Using Genomics (MyDRUG) & Recruiting & NCT03732703 \\
\hline 12 & $\begin{array}{l}\text { Study of Single Agent Belantamab Mafodotin Versus Pomalidomide Plus Low-dose Dexamethasone } \\
\text { (Pom/Dex) in Participants With Relapsed/Refractory Multiple Myeloma (RRMM) }\end{array}$ & Recruiting & NCT04162210 \\
\hline 13 & $\begin{array}{l}\text { A Study of Belantamab Mafodotin (GSK2857916) in Multiple Myeloma Participants With Normal and } \\
\text { Impaired Hepatic Function }\end{array}$ & Recruiting & NCT04398680 \\
\hline
\end{tabular}

(Continued) 
Table 6 (Continued).

\begin{tabular}{|c|c|c|c|}
\hline $\mathbf{S . N}$ & Title & Status & $\begin{array}{l}\text { NCT } \\
\text { Number }\end{array}$ \\
\hline 14 & $\begin{array}{l}\text { A Study of Belantamab Mafodotin (GSK2857916) in Multiple Myeloma Participants With Normal and } \\
\text { Varying Degree of Impaired Renal Function }\end{array}$ & Recruiting & NCT04398745 \\
\hline 15 & $\begin{array}{l}\text { A Study of Belantamab Mafodotin to Investigate Safety, Tolerability, Pharmacokinetics, Immunogenicity } \\
\text { and Clinical Activity in Participants With Relapsed/Refractory Multiple Myeloma (RRMM) }\end{array}$ & $\begin{array}{l}\text { Active, not } \\
\text { recruiting }\end{array}$ & NCT04I77823 \\
\hline 16 & Belantamab Mafodotin in Newly Diagnosed Transplant Eligible Multiple Myeloma Patients & Recruiting & NCT04802356 \\
\hline 17 & Study of Belantamab Mafodotin Plus Standard of Care (SoC) in Newly Diagnosed Multiple Myeloma & Recruiting & NCT0409II26 \\
\hline 18 & $\begin{array}{l}\text { Belantamab Mafodotin Plus Pomalidomide and Dexamethasone (Pd) Versus Bortezomib Plus Pd in } \\
\text { Relapsed/Refractory Multiple Myeloma }\end{array}$ & Recruiting & NCT04484623 \\
\hline 19 & $\begin{array}{l}\text { Evaluation of Efficacy and Safety of Belantamab Mafodotin, Bortezomib and Dexamethasone Versus } \\
\text { Daratumumab, Bortezomib and Dexamethasone in Participants With Relapsed/Refractory Multiple Myeloma }\end{array}$ & Recruiting & NCT04246047 \\
\hline 20 & $\begin{array}{l}\text { Blmf, Lenalidomide and Dexamethasone in Transplant-ineligible Patients With Newly Diagnosed } \\
\text { Multiple Myeloma }\end{array}$ & Recruiting & NCT04808037 \\
\hline 21 & $\begin{array}{l}\text { Study of Belantamab Mafodotin as Pre- and Post-autologous Stem Cell Transplant and Maintenance for } \\
\text { Multiple Myeloma }\end{array}$ & Recruiting & NCT04680468 \\
\hline 22 & $\begin{array}{l}\text { Platform Study of Belantamab Mafodotin as Monotherapy and in Combination With Anti-cancer } \\
\text { Treatments in Participants With Relapsed/Refractory Multiple Myeloma (RRMM) (DREAMM 5) }\end{array}$ & Recruiting & NCT04I 26200 \\
\hline 23 & $\begin{array}{l}\text { A Study to Investigate the Efficacy and Safety of Two Doses of GSK2857916 in Participants With } \\
\text { Multiple Myeloma Who Have Failed Prior Treatment With an Anti-CD38 Antibody }\end{array}$ & $\begin{array}{l}\text { Active, not } \\
\text { recruiting }\end{array}$ & NCT03525678 \\
\hline 24 & $\begin{array}{l}\text { To Evaluate Safety, Tolerability, and Clinical Activity of the Antibody-drug Conjugate, GSK2857916 } \\
\text { Administered in Combination With Lenalidomide Plus Dexamethasone (Arm A), or in Combination } \\
\text { With Bortezomib Plus Dexamethasone (Arm B) in Participants With Relapsed/Refractory Multiple } \\
\text { Myeloma (RRMM) }\end{array}$ & Recruiting & NCT0354428I \\
\hline 25 & $\begin{array}{l}\text { Study Evaluating Safety, Tolerability and Clinical Activity of GSK2857916 in Combination With } \\
\text { Pembrolizumab in Subjects With Relapsed/Refractory Multiple Myeloma (RRMM) }\end{array}$ & $\begin{array}{l}\text { Active, not } \\
\text { recruiting }\end{array}$ & NCT03848845 \\
\hline 26 & $\begin{array}{l}\text { An Open-label, Dose Escalation Study in Japanese Participants With Relapsed/Refractory Multiple } \\
\text { Myeloma Who Have Failed Prior Anti Myeloma Treatments }\end{array}$ & Recruiting & NCT03828292 \\
\hline 27 & Selinexor and Backbone Treatments of Multiple Myeloma Patients & Recruiting & NCT02343042 \\
\hline 28 & Myeloma-Developing Regimens Using Genomics (MyDRUG) & Recruiting & NCT03732703 \\
\hline
\end{tabular}

the management of ocular toxicity. Ocular toxicity also becomes important if the patient has received previous treatment with Sel, as Sel has shown to contribute to blurred vision in $10-11 \%$ of patients and cataract formation in $4 \%$.

Another toxicity worth watchful monitoring with both Sel and belamaf treatment is thromboembolism but is not commonly reported in clinical trials. ${ }^{16,21}$ Thromboembolism prophylaxis may be warranted but is not required. Non-hematological toxicities related to both Sel and belamaf can be managed with standard treatment guidelines. Nausea and vomiting related to Sel may predispose patients to develop AKI. An antiemetic should be added to Sel due to its high emetogenic potential and nausea should be addressed promptly. ${ }^{3}$ Since Dexa is added to the Sel treatment, the treating physician may find that patients do not experience nausea during the initial days of treatment. Instead, they experience delayed nausea and vomiting that will require the additional use of antiemetics.

Sel is also related to neurotoxicity and hyponatremia. The treatment for hyponatremia is usually not required 
until when G3 or 4. Hyponatremia should be expected when patients report unexplained fatigue or slow thought process. Early identification of hyponatremia is crucial as it may worsen with nausea, vomiting, diarrhea, and reduced oral intake. Sodium levels should be monitored at baseline and throughout the treatment. Sel-related hyponatremia usually occurs on day eight or afterward, therefore other hyponatremia causes should be ruled out if it occurs earlier during the course. Neurotoxicity usually develops in the third or fourth week of Sel treatment and manifests as syncope, dizziness, cognitive difficulties, and mental status changes. The treatment should be interrupted and other causes of mental status changes should be ruled out. $^{2,6,21}$

As these are newer drugs with limited data, continuous surveillance and monitoring are strictly warranted during the treatment course with early mitigation strategies. The common AEs and their management strategies have been summarized in Table 5. Various ongoing clinical studies of these two drugs have been summarized in Table 6.

\section{Conclusion}

Cytopenias, constitutional symptoms, gastrointestinal effects, hyponatremia, and anemia are the major toxicities of Sel and belamaf. Managing Sel toxicities require frequent monitoring for blood counts and basic metabolic panel along with prophylactic use of antiemetics, and appetite stimulants as needed and colony-stimulating factors/hematopoietic growth factors in addition to dose interruptions and modifications to manage neutropenia and cytopenia. We recommend following REMS program guidelines for close monitoring and evaluation of belamaf toxicities and early ophthalmic intervention. The physician should be aware of thrombocytopenia and its management as well as belamaf ocular toxicity which is best managed with dose reduction and dose delays but if missed could have serious complications.

\section{Acknowledgments}

Authors thank Ms. Marsha Halajian and Laeth George, MD for providing English language editing services and proofreading.

\section{Disclosure}

F. Anwer reports personal fees from Bristol Myers Squibb as a speaker and fee from Janssen pharmaceutical as an advisory board member, this fee was not related to the submitted work. Without receiving direct funding, served as the local principal investigator for Allogene Therapeutics, Celgene, GlaxoSmithKline, and Bristol Myers Squibb; has a consulting or advisory role for Seattle Genetics, Incyte Corporation Speakers' Bureau, Company: Incyte Corporation; receives travel and accommodations expenses from Seattle Genetics, Incyte; receives honoraria from Incyte, Company: Seattle Genetics; and received research funding from Seattle Genetics, Company: Celgene, Acetylon Pharmaceuticals, Millennium, Astellas Pharma and AbbVie; and reports no other potential conflicts of interest for this work. The other authors report no conflicts of interest for this work.

\section{References}

1. Siegel RL, Miller KD, Jemal A. Cancer statistics, 2020. CA Cancer J Clin. 2020;70(1):7-30. doi:10.3322/caac. 21590

2. Chen C, Siegel D, Gutierrez M, et al. Safety and efficacy of selinexor in relapsed or refractory multiple myeloma and waldenstrom macroglobulinemia. Blood. 2018;131(8):855-863. doi:10.1182/blood-2017-08-797886

3. Bahlis NJ, Sutherland H, White D, et al. Selinexor plus low-dose bortezomib and dexamethasone for patients with relapsed or refractory multiple myeloma. Blood. 2018;132(24):2546-2554. doi:10.1182/blood-2018-06-858852

4. Syed YY. Selinexor: first global approval. Drugs. 2019;79(13):14851494. doi:10.1007/s40265-019-01188-9

5. Vogl DT, Dingli D, Cornell RF, et al. Selective inhibition of nuclear export with oral selinexor for treatment of relapsed or refractory multiple myeloma. J Clin Oncol. 2018;36(9):859-866. doi:10.1200/ JCO.2017.75.5207

6. Chari A, Vogl DT, Gavriatopoulou M, et al. Oral selinexor-dexamethasone for triple-class refractory multiple myeloma. $N$ Engl $J$ Med. 2019;381(8):727-738. doi:10.1056/NEJMoa1903455

7. US-FDA. FDA grants accelerated approval to selinexor for multiple myeloma. 2019. Available from: https://www.fda.gov/drugs/ resources-information-approved-drugs/fda-grants-acceleratedapproval-selinexor-multiple-myeloma. Accessed December, 2020.

8. Walker JS, Garzon R, Lapalombella R. Selinexor for advanced hematologic malignancies. Leuk Lymphoma. 2020;61(10):2335-2350.

9. Grosicki S, Simonova M, Spicka I, et al. Once-per-week selinexor, bortezomib, and dexamethasone versus twice-per-week bortezomib and dexamethasone in patients with multiple myeloma (BOSTON): a randomised, open-label, Phase 3 trial. Lancet. 2020;396 (10262):1563-1573. doi:10.1016/S0140-6736(20)32292-3

10. Malandrakis P, Ntanasis-Stathopoulos I, Gavriatopoulou M, Terpos E. Clinical utility of selinexor/dexamethasone in patients with relapsed or refractory multiple myeloma: a review of current evidence and patient selection. Onco Targets Ther. 2020;13:6405-6416. doi: $10.2147 /$ OTT.S227166

11. Abramson HN. B-Cell Maturation Antigen (BCMA) as a target for new drug development in relapsed and/or refractory multiple myeloma. Int $J$ Mol Sci. 2020;21(15):5192. doi:10.3390/ijms21155192

12. Cho SF, Lin L, Xing L, et al. BCMA-targeting therapy: driving a new era of immunotherapy in multiple myeloma. Cancers. 2020;12(6):129. doi:10.3390/cancers 12061473

13. US-FDA. FDA granted accelerated approval to belantamab mafodotin-blmf for multiple myeloma. 2020. Available from: https://www. fda.gov/drugs/drug-approvals-and-databases/fda-granted-acceleratedapproval-belantamab-mafodotin-blmf-multiple-myeloma. Accessed November 25, 2020. 
14. Markham AJD. Belantamab mafodotin: first approval. Drugs. 2020;1-7. doi:10.1007/s40265-019-01241-7

15. Lonial S, Lee HC, Badros A, et al. Belantamab mafodotin for relapsed or refractory multiple myeloma (DREAMM-2): a two-arm, randomised, open-label, Phase 2 study. Lancet Oncol. 2020;21 (2):207-221. doi:10.1016/S1470-2045(19)30788-0

16. Trudel S, Lendvai N, Popat R, et al. Targeting B-cell maturation antigen with GSK2857916 antibody-drug conjugate in relapsed or refractory multiple myeloma (BMA117159): a dose escalation and expansion Phase 1 trial. Lancet Oncol. 2018;19(12):1641-1653. doi:10.1016/S1470-2045(18)30576-X

17. Trudel S, Lendvai N, Popat R, et al. Antibody-drug conjugate, GSK2857916, in relapsed/refractory multiple myeloma: an update on safety and efficacy from dose expansion phase I study. Blood Cancer J. 2019;9(4):37. doi:10.1038/s41408-019-0196-6

18. Trudel S, Cohen AD, Richardson PG, et al. Safety and tolerability of single-agent belantamab mafodotin in heavily pre-treated patients with relapsed/refractory multiple myeloma: pooled data from DREAMM-1 and DREAMM-2. HemaSphere. 2020;4:429-430.

19. Farooq AV, Degli Esposti S, Popat R, et al. Corneal epithelial findings in patients with multiple myeloma treated with antibody-drug conjugate belantamab mafodotin in the pivotal, randomized, DREAMM2 Study. Ophthalmol Ther. 2020;9(4):889-911.

20. Razak ARA, Mau-Soerensen M, Gabrail NY, et al. First-in-class, first-in-human phase I study of selinexor, a selective inhibitor of nuclear export, in patients with advanced solid tumors. $J$ Clin Oncol. 2016;34(34):4142.

21. Jakubowiak AJ, Jasielec JK, Rosenbaum CA, et al. Phase 1 study of selinexor plus carfilzomib and dexamethasone for the treatment of relapsed/refractory multiple myeloma. Br J Haematol. 2019;186 (4):549-560. doi:10.1111/bjh.15969

22. Navari RM, Qin R, Ruddy KJ, et al. Olanzapine for the prevention of chemotherapy-induced nausea and vomiting. $N$ Engl J Med. 2016;375 (2):134-142. doi:10.1056/NEJMoa1515725

23. Bahlis N, Chen C, Sebag M, et al. A phase $1 \mathrm{~B} / 2$ study of selinexor in combination with backcone therapies for treatment of relapsed/refactory multiple myeloma. Haematologica Conf. 2016;101:84.

24. Ruiz Garcia V, López-Briz E, Carbonell Sanchis R, Gonzalvez Perales JL, Bort-Marti S. Megestrol acetate for treatment of anorexia-cachexia syndrome. Cochrane Database Syst Rev. 2013;2013(3): Cd004310.

25. Jatoi A, Windschitl HE, Loprinzi CL, et al. Dronabinol versus megestrol acetate versus combination therapy for cancer-associated anorexia: a North Central Cancer Treatment Group study. J Clin Oncol. 2002;20(2):567-573. doi:10.1200/JCO.2002.20.2.567

26. Chen CI, Bahlis N, Gasparetto C, et al. Selinexor, pomalidomide, and dexamethasone (SPd) in patients with relapsed or refractory multiple myeloma. Blood. 2019;134.

27. Andreyev J, Ross P, Donnellan C, et al. Guidance on the management of diarrhoea during cancer chemotherapy. Lancet Oncol. 2014;15 (10):e447-e460. doi:10.1016/S1470-2045(14)70006-3

28. Sun JX, Yang N. Role of octreotide in post chemotherapy and/or radiotherapy diarrhea: prophylaxis or therapy? Asia Pac J Clin Oncol. 2014;10(2):e108-e113. doi:10.1111/ajco.12055

Journal of Blood Medicine

\section{Publish your work in this journal}

The Journal of Blood Medicine is an international, peer-reviewed, open access, online journal publishing laboratory, experimental and clinical aspects of all aspect pertaining to blood based medicine including but not limited to: Transfusion Medicine; Blood collection, Donor issues, Transmittable diseases, and Blood banking logistics; Immunohematology; Artificial and alternative blood based
29. Hovan AJ, Williams PM, Stevenson-Moore P, et al. A systematic review of dysgeusia induced by cancer therapies. Support Care Cancer. 2010;18(8):1081-1087. doi:10.1007/s00520-010-0902-1

30. Park SE, Hwang JH, Choi JH, et al. Incidence, risk factors, and clinical outcomes of acute kidney injury caused by palliative chemotherapy in lung cancer. $J$ Cancer. 2019;10(22):5332-5338. doi: $10.7150 /$ jca. 28399

31. Eaton JS, Miller PE, Mannis MJ, Murphy CJ. Ocular adverse events associated with antibody-drug conjugates in human clinical trials. $J$ Ocul Pharmacol Ther. 2015;31(10):589-604. doi:10.1089/jop.2015. 0064

32. Fathi AT, Chen R, Trippett TM, et al. Interim Analysis of a Phase 1 Study of the Antibody-Drug Conjugate SGN-CD19A in Relapsed or Refractory B-Lineage Acute Leukemia and Highly Aggressive Lymphoma. Washington, DC: American Society of Hematology; 2014.

33. Moskowitz CH, Forero-Torres A, Shah BD, et al. Interim Analysis of a Phase 1 Study of the Antibody-Drug Conjugate SGN-CD19A in Relapsed or Refractory B-Lineage Non-Hodgkin Lymphoma. Washington, DC: American Society of Hematology; 2014.

34. Eliason L, Opalinska J, Martin ML, et al. Dreamm-1: patient perspectives from the first-in-human study of single-agent belantamab mafodotin for relapsed and refractory multiple myeloma (RRMM). HemaSphere. 2020;4:936.

35. Popat R, Warcel D, O'Nions J, et al. Characterisation of response and corneal events with extended follow-up after belantamab mafodotin (GSK2857916) monotherapy for patients with relapsed multiple myeloma: a case series from the first-time-in-human clinical trial. Haematologica. 2020;105(5):e261. doi:10.3324/haematol.2019.235 937

36. Accessdata.fda.gov. BLENREP (belantamab mafodotin-blmf) for injection, for intravenous use. 2020. Available from: https://www. accessdata.fda.gov/drugsatfda_docs/label/2020/761158s000lbl.pdf. Accessed February 1, 2021.

37. Goldschmidt H, Ashcroft J, Szabo Z, Garderet L. Navigating the treatment landscape in multiple myeloma: which combinations to use and when? Ann Hematol. 2019;98(1):1-18. doi:10.1007/s00277018-3546-8

38. Gandhi UH, Cornell RF, Lakshman A, et al. Outcomes of patients with multiple myeloma refractory to $\mathrm{CD} 38$-targeted monoclonal antibody therapy. Leukemia. 2019;33(9):2266-2275. doi:10.1038/s413 75-019-0435-7

39. Machlus KR, Wu SK, Vijey P, et al. Selinexor-induced thrombocytopenia results from inhibition of thrombopoietin signaling in early megakaryopoiesis. Blood. 2017;130(9):1132-1143. doi:10.1182/ blood-2016-11-752840

40. Gavriatopoulou M, Chari A, Chen C, et al. Integrated safety profile of selinexor in multiple myeloma: experience from 437 patients enrolled in clinical trials. Leukemia. 2020;34(9):2430-2440. doi:10.1038/ s41375-020-0756-6 therapeutics; Hematology; Biotechnology/nanotechnology of blood related medicine; Legal aspects of blood medicine; Historical perspectives. The manuscript management system is completely online and includes a very quick and fair peer-review system. Visit http://www.dovepress.com/testimonials.php to read real quotes from published authors. 